Portland State University

PDXScholar

$10-2013$

\title{
Durability Assessment of Recycled Concrete Aggregates for use in New Concrete: Phase I - Revised
}

\author{
Jason $\mathrm{H}$. Ideker \\ Oregon State University \\ Matthew P. Adams \\ Oregon State University \\ Jennifer Tanner \\ University of Wyoming \\ Angela Jones \\ University of Wyoming
}

Follow this and additional works at: https://pdxscholar.library.pdx.edu/trec_reports

Part of the Transportation Commons, Urban Studies Commons, and the Urban Studies and Planning Commons

Let us know how access to this document benefits you.

\section{Recommended Citation}

Ideker, Jason H., Matthew P. Adams, Jennifer Tanner, Angela Jones. Durability Assessment of Recycled Concrete Aggregates for use in New Concrete: Phase I - Revised. OTREC-RR-11-09. Portland, OR: Transportation Research and Education Center (TREC), 2013. https://doi.org/10.15760/trec.15

This Report is brought to you for free and open access. It has been accepted for inclusion in TREC Final Reports by an authorized administrator of PDXScholar. Please contact us if we can make this document more accessible: pdxscholar@pdx.edu. 


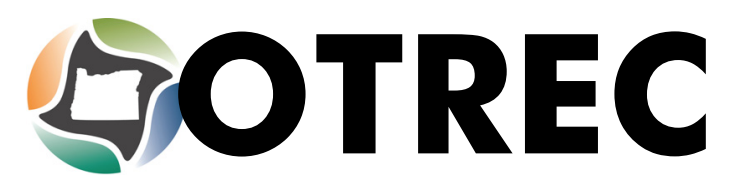

ORECON
TRANSPORTATION

RESEARCH AND

FINAL REPORT

\title{
Durability Assessment of Recycled Concrete Aggregates for Use in New Concrete
}

\author{
Phase I - Revised
}

OTREC-RR-11-09

October 2013 



\title{
DURABILITY ASSESSMENT OF RECYCLED CONCRETE AGGREGATES FOR USE IN NEW CONCRETE
}

\author{
Phase I - Report
}

\section{OTREC-RR-11-09 Revision 1}

\author{
by \\ Jason H. Ideker, Ph.D., PI \\ Assistant Professor \\ jason.ideker@oregonstate.edu \\ Matthew P. Adams, Graduate Research Assistant \\ Oregon State University \\ Jennifer Tanner, Ph.D., P.E., Co-PI \\ Associate Professor \\ tannerj@uwyo.edu
}

Angela Jones, Graduate Research Assistant

University of Wyoming

for

Oregon Transportation Research and Education Consortium (OTREC)

P.O. Box 751

Portland, OR 97207

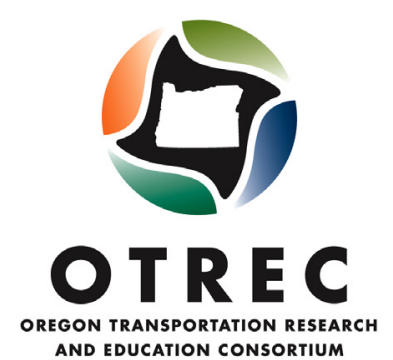

October 2013 



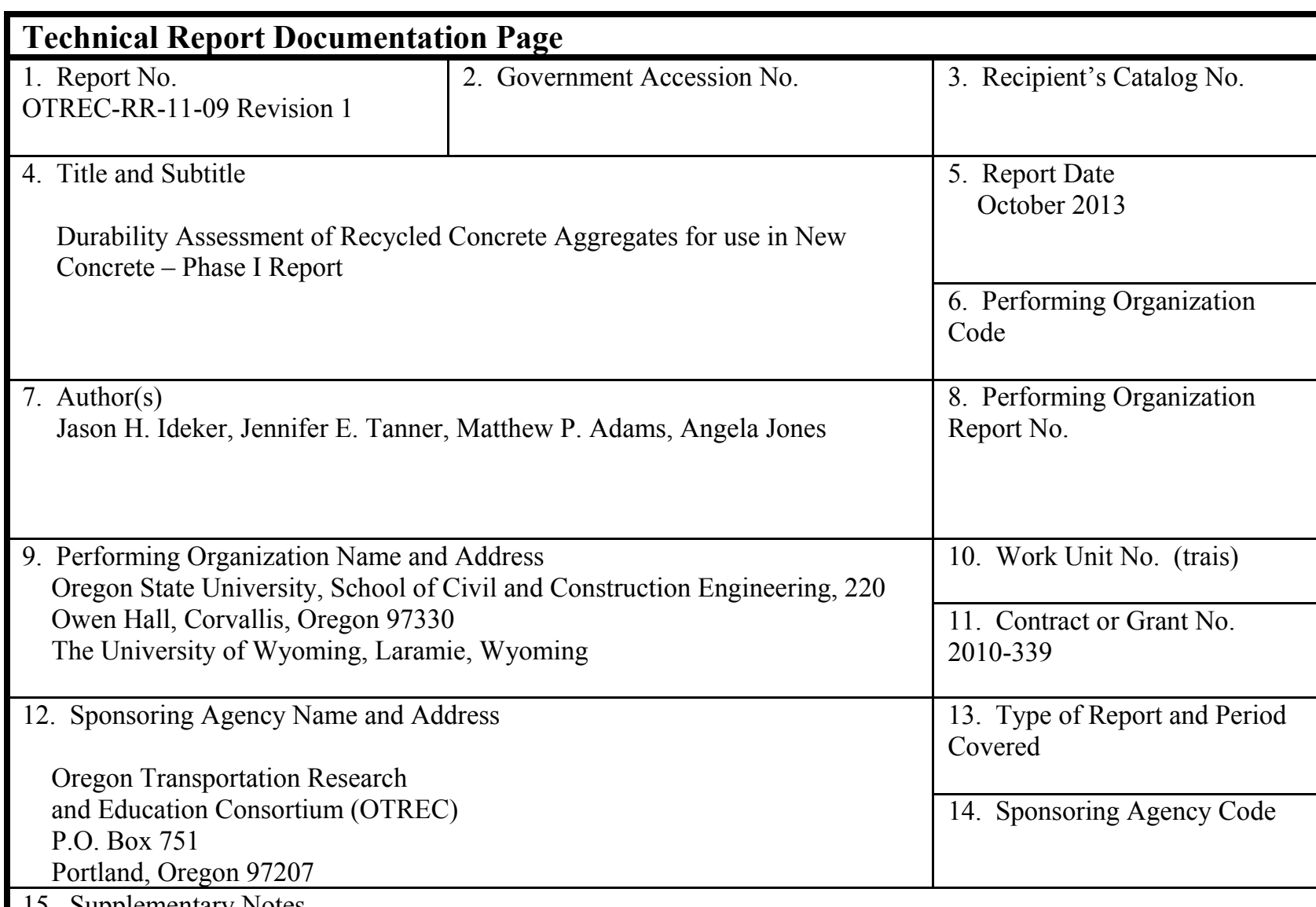

15. Supplementary Notes

16. Abstract

The primary goal of this research project was to investigate the long-term durability of concrete incorporating recycled concrete aggregate (RCA) through accelerated laboratory testing. Overall it was found that modifications to standard aggregate testing and characterization standards were necessary for testing RCA. This included modifications to standard tests including ASTM C 128, C 305 and C 1260. It was found that the potential for alkalisilica reactivity did exist for new concrete containing RCA. The characteristics of the RCA also had a profound effect on ASR related expansion. RCA with a higher content of reactive coarse or fine aggregate (compared to paste fraction) exhibited greater reaction and would therefore require higher levels of mitigation. Based on testing in this research project precision and bias statements in ASTM C 1260 (for virgin aggregate) do not apply to RCA.

Recommendations for future work are also included in this report.

17. Key Words

Recycled concrete aggregate, alkali-silica reaction, accelerated testing, testing methods, durability, long-term performance
18. Distribution Statement No restrictions. Copies available from OTREC: www.otrec.us
19. Security Classification (of this report)

Unclassified

\begin{tabular}{|l|c|}
$\begin{array}{l}\text { 20. Security Classification (of this } \\
\text { page) }\end{array}$ & 21. No. of Pages \\
Unclassified & 66 \\
\hline
\end{tabular}




\section{ACKNOWLEDGEMENTS}

This project was funded by the Oregon Transportation Research and Education Consortium (OTREC), Oregon State University and the University of Wyoming. Their support is greatly appreciated. The authors also wish to thank Dr. Benoit Fournier and Dr. Medhat Shehata for participating in the interlaboratory study in this project, providing several sources of recycled concrete aggregates and for their thoughtful insight and collegiality.

\section{DISCLAIMER}

The contents of this report reflect the views of the authors, who are solely responsible for the facts and the accuracy of the material and information presented herein. This document is disseminated under the sponsorship of the U.S. Department of Transportation University Transportation Centers Program in the interest of information exchange. The U.S. Government assumes no liability for the contents or use thereof. The contents do not necessarily reflect the official views of the U.S. Government. This report does not constitute a standard, specification, or regulation. 


\section{TABLE OF CONTENTS}

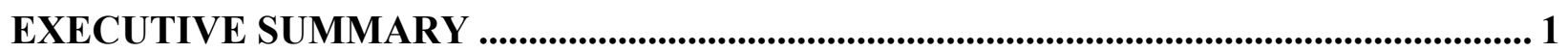

1.0 INTRODUCTION AND LITERATURE REVIEW ............................................5

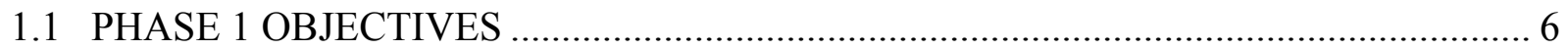

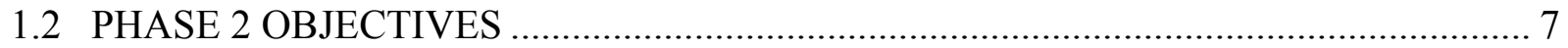

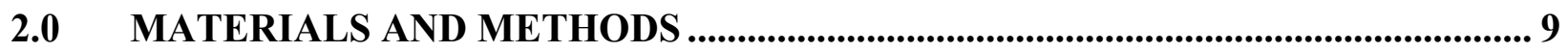

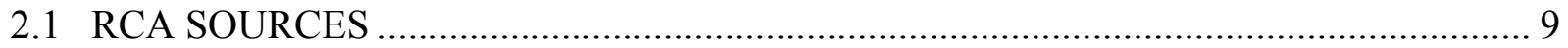

2.2 CEMENTITIOUS MATERIALS TESTING ……...................................................... 13

2.3 AGGREGATE CHARACTERIZATION-MODIFICATION TO STANDARD

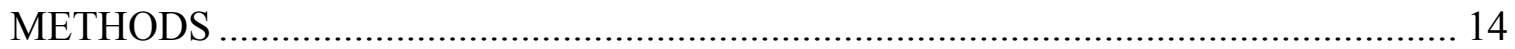

2.3.1 ASTM C 128 - Specific Gravity and Absorption Capacity Testing of Fine

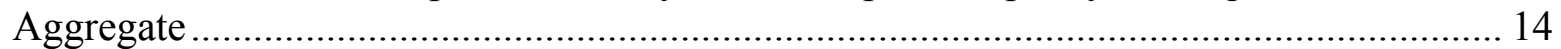

2.3.2 ASTM C 305 - Mortar Mixing Procedure ……………………............................... 15

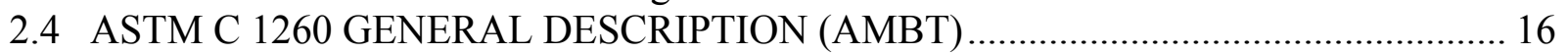

2.4.1 Discussion of ASTM C 1260 testing method ..................................................... 17

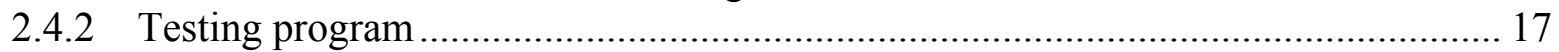

2.4.3 Modifications to ASTM C 1260 Test Method - RCA Washing ................................ 18

2.4.4 Modifications to ASTM C 1260 Test Method - Crusher's Fines.............................. 19

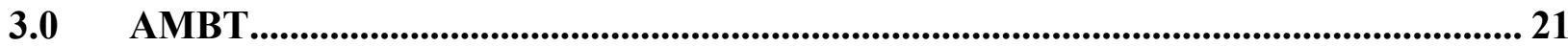

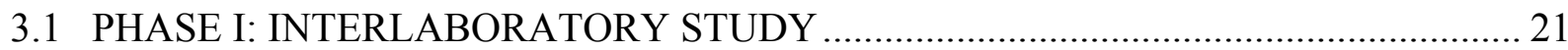

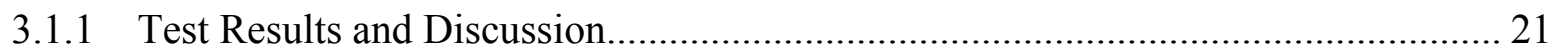

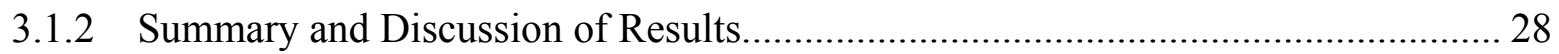

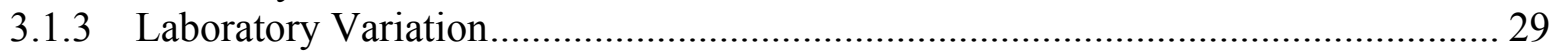

3.2 PHASE 2: UNIVERSITY OF WYOMING STUDY - PRELIMINARY RESULTS ..... 35

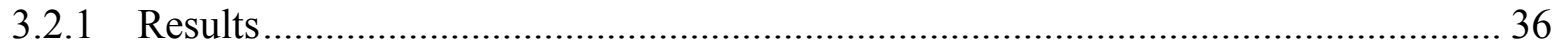

4.0 DEPARTMENT OF TRANSPORTATION SURVEY _............................................ 39

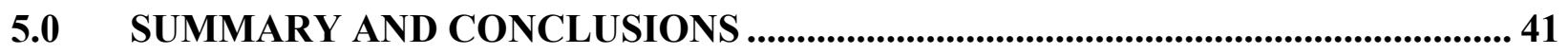

6.0 REFERENCES.............................................................................................................. 43

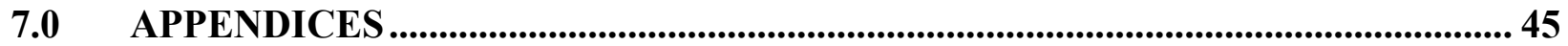

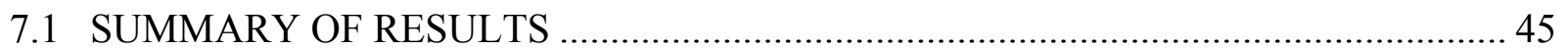

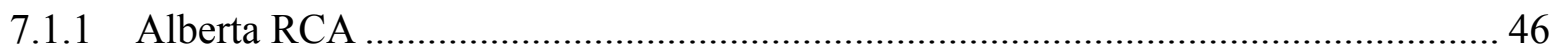

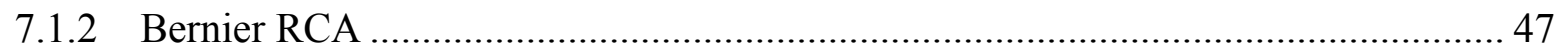

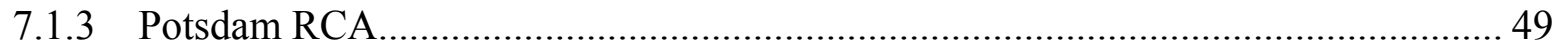

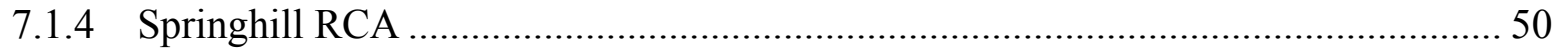

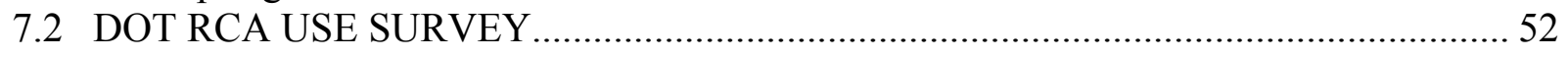




\section{LIST OF TABLES}

Table 2.1: RCA Sources from Reactive Aggregates from Outdoor Exposure Block Testing..... 10 Table 2.2: Nonreactive Aggregate Used in Combination with RCA for Laboratory Testing ..... 13

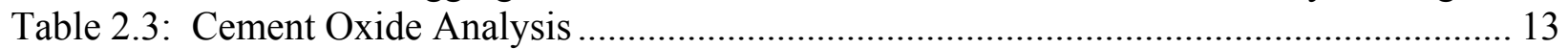

Table 2.4: Number of Specimen Sets for Each Crushed Coarse Aggregate Proportion................ 18

Table 2.5: Required Number of Specimen Sets for Each Crusher's Fines Proportion................... 18

Table 2.6: Aggregate Material Requirements for Various Proportions in the Study..................... 18

Table 3.1: ASTM Averages and Precision for crushers fines RCA ……..................................... 30

Table 3.2: ASTM Averages and Precision for Re-Crushed Coarse RCA .................................... 31

Table 3.3: ASTM Within-Laboratory Averages and COV for Each University for Re-crushed

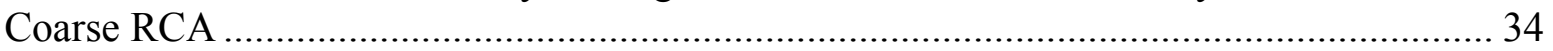

Table 3.4: ASTM Within-Laboratory Averages and COV for Each University for Crusher's Fines 34

Table 3.5: Material Requirements for Each RCA and Aggregate Type Mixture ...................... 36

Table 3.6: Fourteen-Day Averages and ASTM Precision for Each RCA and Aggregate Type .. 38

\section{LIST OF FIGURES}

Figure 2-1: Jaw Crusher at Oregon State University ……....................................................... 12

Figure 2-2: Pulverizer at Oregon State University ................................................................ 12

Figure 3-1: Expansion from 0 to 28 days for 100\% Potsdam and 100\% Alberta Re-crushed

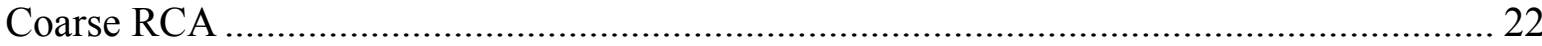

Figure 3-2: Expansion from 0 to 28 days for 100\% Potsdam and 100\% Alberta Crusher's Fines.... 23

Figure 3-3: Average 14-day results at four university laboratories for 50\% Alberta RCA.......... 24

Figure 3-4: Average 14-day results at four university laboratories for 50\% Bernier RCA.......... 25

Figure 3-5: Average 14-day results at four university laboratories for 50\% Potsdam RCA ........ 26

Figure 3-6: Average 14-day results at four university laboratories for 50\% Springhill RCA ...... 27

Figure 3-7: Average expansion of 14-day results for re-crushed coarse RCA proportions........... 28

Figure 3-8: Average expansion of 14-day results for crusher's fines .......................................... 29

Figure 3-9: ASTM C1260 Precision Limits vs. Inter-Laboratory Study Data for Crusher's Fines

RCA 32

Figure 3-10: ASTM C1260 Precision Limits vs. Inter-Laboratory Study Data for Re-crushed RCA 33

Figure 3-11: Average 14-day expansion results for each mixture proportion .............................. 37

Figure 7-1: Fourteen-day results from each laboratory for 100\% Alberta RCA ........................... 46

Figure 7-2: Fourteen-day results from each laboratory for 50\% Alberta RCA ............................. 46

Figure 7-3: Fourteen-day results from each laboratory for 25\% Alberta RCA ………….............. 47

Figure 7-4: Fourteen-day results from each laboratory for 100\% Bernier RCA ........................... 47

Figure 7-5: Fourteen-day results from each laboratory for 50\% Bernier RCA ............................ 48

Figure 7-6: Fourteen-day results from each laboratory for 25\% Bernier RCA ………................. 48

Figure 7-7: Fourteen-day results from each laboratory for 100\% Potsdam RCA ..................... 49

Figure 7-8: Fourteen-day results from each laboratory for 50\% Potsdam RCA …………............ 49

Figure 7-9: Fourteen-day results from each laboratory for $25 \%$ Potsdam RCA …………........... 50

Figure 7-10: Fourteen-day results from each laboratory for 100\% Springhill RCA .....................5 50

Figure 7-11: Fourteen-day results from each laboratory for 50\% Springhill RCA ...................... 51

Figure 7-12: Fourteen-day results from each laboratory for 25\% Springhill RCA ....................... 51 


\section{EXECUTIVE SUMMARY}

This research project, started in the 2009-2010 funding cycle, had the primary goal of investigating the long-term durability of concrete incorporating recycled concrete aggregate (RCA) through accelerated laboratory testing. Of particular interest was the possibility of pronounced alkali-silica reaction (ASR), an expansive reaction that results in cracking and a reduction in the service life of concrete structures, in new concrete incorporating RCA which may have active ASR. This area of concern was identified by several states as a major research need in a recent Federal Highway Administration study.

Currently the use of recycled concrete as aggregate in the United States is predominately limited to use in pavement base or subbase material and nonstructural fill, with the remainder being landfilled. As the availability of natural aggregate sources is reduced and government initiatives, as well as public demand, push the use of sustainable construction practices, the need for alternative aggregate sources will continue. One of the most logical and environmentally friendly practices is recycling concrete taken out of service into a source of aggregate for new construction. This is a common practice in the asphalt materials, aluminum, steel and glass industries. This lack of widespread use is centered on a lack of scientific evidence showing how RCA can be used effectively and efficiently while meeting the same construction goals as other, more established construction methodologies. Of particular concern is a stigma that RCA is a substandard material and that long-term performance (e.g., durability and serviceability) cannot be guaranteed. No uniform guidance from the federal level has been made available to ensure that designers, specifiers and contractors use RCA in a consistent and reliable manner.

The first phase of this project had the following objectives:

- Develop guidance for how to assess RCA sources for potentially deleterious-related ASR.

- Identify accelerated laboratory testing methods that will provide prediction of ASR in concrete incorporating RCA.

- Identify potential mitigation strategies through performance testing that will ensure durability of mixtures containing RCA where ASR could potentially limit long-term performance.

- Generate benchmark data crucial for the acceptance of RCA in paving and structural concrete mixtures.

- Disseminate results of research through OTREC published reports and documents and through presentation at key national meetings (e.g., TRB and/or ACI).

- Expand existing literature and state-of-knowledge in this area and bring new expertise to the states of Oregon and Wyoming related to the long-term durability of concrete incorporating RCA. 
A unique opportunity arose for the research team on this project to establish collaboration with two additional universities. Dr. Benoit Fournier (formerly of CANMET-MTL) is an associate professor at Université Laval in Quebec City, Quebec, Canada, and Dr. Medhat Shehata is an assistant professor at Ryerson University in Toronto, ON, Canada. Dr. Fournier is a worldrenowned ASR researcher with over 25 years of experience focusing on testing methods and characterization of the reaction from a petrographic perspective. He recently has started investigations into RCA as sources of virgin aggregate have decreased and demand for sustainable construction practices in Canada has increased. Dr. Shehata has the longest tenure working on RCA, starting with his dissertation research topic and continuing through his six years as an assistant professor. This collaboration allowed four universities to work on the same sources of recycled concrete aggregate (detailed in Section 2.1).

As a result of the collaboration with research teams at Laval and Ryerson, the scope of the project and objectives for Phase I were modified. All Phase I objectives will still be met. However, it was necessary to shift research priorities slightly between the project's two phases. In short, more verification of accelerated testing methods was performed in Phase I, resulting in a larger testing matrix for accelerated testing at both Oregon State University and the University of Wyoming. Objective 5 - DOT survey and database collection - was therefore not started until late in Phase I. The survey sent to state DOTs is included and summarized in Section 4.0. Full results of this survey will be included in the Phase II report.

This report will cover the following sections:

1.0 - Introduction

2.0 - Materials and Methods

3.0 - AMBT Testing

4.0 - Department of Transportation Survey

5.0 - Summary and Conclusions

6.0 - References

7.0 - Appendices

Overall, the research team found that results from the ASTM C 1260 testing method could be replicated for the RCA sources investigate in this project. The team found that even though the RCA incorporated into ASTM C 1260 specimens had already undergone deleterious ASR in the field, there was still potential for expansion with certain RCA sources. The procedure used to crush the RCA to the appropriate gradation for the ASTM C1260 test can also have an impact on the level of reaction. The variation in multi-laboratory testing was higher than that for virgin reactive aggregate testing. While the four laboratories do not represent a minimum number of laboratories on which to base a precision and bias summary (ASTM recommends a minimum of six for an interlaboratory precision and bias statement), the COVs for a single group range from $13.6 \%$ to $94.1 \%$. The latter is considerably higher than the multi-laboratory COV of $43 \%$ as specified by ASTM C 1260. A full set of variation data is presented in Section 3.1.2.

The testing done as part of this research project also found the following outcomes:

- Modifications to standard aggregate testing and characterization standards are necessary for RCA. 
- Absorption capacity testing required at least a 24-hour soaking period to take up $95 \%$ of the aggregate's total absorption.

- Modifications to ASTM C 305 were required for properly mixing mortars containing RCA, including a soaking period of 30 minutes for all aggregate (including RCA) to ensure proper absorption by dry aggregate and adequate mixing.

- Based on testing in this research project, precision and bias statements in ASTM C 1260 (for virgin aggregate) do not apply to RCA. Additional testing from at least six laboratories testing the same materials would be needed to properly establish precision and bias statements. 


\subsection{INTRODUCTION AND LITERATURE REVIEW}

The U.S. Department of Transportation reported that a goal for fiscal years 2006-2011 would involve improving "DOT-owned or controlled facilities for the benefit of host communities by energy conservation, preventing pollution, recycling, and using recycled products" (Strategic Plan F-Y2). As the need grows for environmentally sustainable work practices, the construction industry seeks ways to reduce or recycle waste from both construction and demolition processes. One of the largest components of building demolition waste is concrete. According to a Federal Highway Administration (FHWA) survey, 41 states currently use recycled concrete in construction, but most of these states limit its use to base or subbase applications. (FHWA, 2003) While this is a positive trend, the use of recycled concrete aggregate (RCA) has greater potential for helping the U.S. DOT meet its environmental stewardship goals.

Previous research has illustrated RCA's past use in new concrete and its ability to meet the compression strength requirements (Shayan and $\mathrm{Xu}, 2003$ ) as well as the flexural performance requirements (Fathifazl and coworkers, 2009) of normal strength concretes. The durability and longevity of concrete containing RCA is, however, still a main concern. Durability, in particular, is affected by the condition of the recycled concrete being crushed for use in new applications. If that concrete had deteriorated during its service life, detrimental effects may be passed on to the new concrete. These effects can become difficult to monitor and mitigate when recycled concrete from more than one source is used on the same project.

Alkali-silica reaction (ASR) is one of several pre-existing deterioration mechanisms that may limit the long-term performance of concrete containing RCA. While ASR can jeopardize the durability of concrete, it can be mitigated if the virgin aggregate is initially identified as reactive. However, it has been shown that adding recycled concrete that has exhibited ASR in the field requires higher ratios of mitigating agents (Scott and Gress, 2003; Stark, 1996). This issue highlights the need for a standard test that will quickly and efficiently determine the potential field reactivity of RCA. Currently, no such test exists.

The most used accelerated test method for ASR on virgin aggregates is the ASTM C1260 Accelerated Mortar Bar Test. Another available test includes the ASTM C 1293, but it is not an option for this study due to the yearlong required testing period of ASTM C 1293. The other options offer a faster testing period but often at the expense of accuracy (Thomas, 2006). Since it has been shown that, on average, aggregates expand more quickly in warmer conditions than cooler conditions (Fournier, 2009), and these accelerated tests require extreme temperatures for testing, results are obtained faster. While it can produce false results, ASTM C 1260 is generally accepted as a good screening test for aggregates (Fournier, 2006).

The best approach for accurate prediction of reactivity is the use of several complimentary tests. However, when separate tests produce opposite results (e.g., one passing result and one failing result), the test with the worst result, or the most conservative result, should be taken into consideration and preference should be given to the more reliable, longer-term ASTM C 1293 test results (Fournier and Berubé, 2007). 
Another concern when using RCA is that the level of processing during the crushing activities may affect its reactivity. It has been shown that additional crushing procedures increase the amount of cracks in the original coarse aggregate of the RCA (Nagataki and coworkers, 2004). This may expose fresh reaction sites within the RCA for ASR to occur. The effect of two different levels of crushing is examined in this report.

Many mitigation strategies for ASR are available within the construction industry. Generally, the needed quantity of these mitigating materials depends on their composition and the reactive nature of the aggregate to be mitigated. There is contention that ASTM C 1260 is not adequate for testing RCA due to the amount of crushing involved (Scott and Gress, 2003), but it is possible to use ASTM C 1260 to determine the needed ratio of mitigating agents for virgin aggregates (Thomas, 2005; Fournier and Molhatra, 1999). Common mitigation measures include class $\mathrm{C}$ or F fly ash, silica fume, lithium nitrate, blast furnace slag, and/or low alkali cement. The main objective of this research was to find a quick and accurate way to assess the long-term effects of incorporating RCA into new concrete. Research focused primarily on RCA that exhibited ASR in field conditions. The research presented in this report was focused on evaluating the accuracy of current accelerated testing methods for detecting ASR in recycled concrete. Phase 2 (currently underway) will focus on assessing various mitigation strategies of ASR in RCA.

The PI on this project has a long-standing collaboration with Dr. Fournier and it was apparent that this project would afford a unique opportunity to better characterize applicability of accelerated laboratory testing methods to characterize potential alkali-silica reactivity of RCA. A critical need identified by the research team was to determine the repeatability of such testing methods when testing aggregate sources in multiple laboratories. This type of data is essential to establish testing methods for this type of material through organizations such as ASTM, ACI, FHWA, CSA and AASHTO. This collaboration allowed four universities to work on the same sources of recycled concrete aggregate (detailed in Section 2.1). Aggregates were obtained from two outdoor long-term exposure sites: CANMET exposure site in Ottawa, ON, Canada The PI and co-PI on this project have a strong relationship with researchers at CANMET..

\subsection{PHASE 1 OBJECTIVES}

This phase focused on whether ASTM C 1260 could adequately determine the reactivity of mortars incorporating varying replacement levels of RCA. Because aggregate size requirements for ASTM C 1260 involve extensive crushing and could remove fractions of RCA that would otherwise be reactive, multiple levels of crushing of the RCA were examined. In addition, the original procedural steps for ASTM C 1260 were modified due to higher absorption rates in RCAs than regular aggregate.

State surveys performed by FHWA indicated a need for increased quality control and quality assurance in the use of RCA in new applications (FHWA, 2003). It was thus advantageous to include the two additional research teams (Laval and Ryerson) to expand the statistical reliability of the overall results. 
The RCAs used in this research came from large concrete block specimens at an Ottawa location. These blocks displayed expansions from ASR in the field. The blocks were crushed and samples distributed to the four participating universities. Four types of RCA were reviewed: Bernier, Potsdam, Alberta and Springhill. Bernier, Springhill and Potsdam come from a sedimentary geologic environment and contain varying forms of reactive rock types: virgin Bernier aggregate is siliceous/argillaceous limestone, virgin Springhill aggregate is a mixture of greywacke and argillite, and virgin Potsdam aggregate is siliceous sandstone. Virgin Alberta aggregate is natural gravel composed of fragments of sandstone, limestone, quartzite, and fine-grained volcanic rocks.

\subsection{PHASE 2 OBJECTIVES}

Further multi-laboratory testing on an additional three RCA between the University of Wyoming and Oregon State University will be performed as a part of Phase II. Additionally, two RCAs that are classified as reactive will be examined to determine if mitigation techniques can be used to incorporate RCA into new concrete. Therefore, the second phase of this research will consist of testing both a highly and moderately reactive aggregate. 


\subsection{MATERIALS AND METHODS}

Currently, the University of Wyoming is testing a mitigation hypothesis that combines two reactive aggregates within the same ASTM C 1260 test. The hypothesis of this research is that the pessimum effect could become an important mitigation technique by catalyzing the ASR process. The pessimum proportion is the proportion of reactive silica to available alkali which will produce the highest level of expansion (e.g., greatest ASR-induced expansion) in a concrete or mortar mixture. It is well documented that reactive silica or reactive alkali in excess of this proportion will result in lower expansions. A way of thinking about this is that by combining two reactive aggregates in a concrete mixture while holding the level of available alkali constant, a lower level of ASR may be expected than if one reactive aggregate was combined with that same amount of available alkali (Hobbs, 1998). It has been observed in other testing that by either overburdening the system with reactive silica or alkali expansions, ASR-related damage can be reduced. This phase of testing began in early November 2010 and is ongoing. Preliminary data is presented in Section 3.2. Additional work includes three field specimens to compare accelerated test methods with long-term field data. For Phase I, seven types of recycled concrete aggregate were investigated. The research team sought out collaborative efforts with researchers at two Canadian universities: Dr. Benoit Fournier at Université Laval in Quebec City, Quebec, and Dr. Medhat Shehata at Ryerson University in Toronto, Ontario. Both Drs. Fournier and Shehata have been working on recycled concrete aggregates and the potential for alkali-silica reaction for a combined total of 10 years. The research teams at OSU and UW were fortunate to establish a strong collaboration with these researchers, which resulted in the ability to initiate and perform a large interlaboratory study on the efficacy of ASTM C 1260 to detect aggregate reactivity from RCA and on the repeatability of testing results. This is the first largescale attempt to correlate the results of ASR testing on RCA from the same sources, tested at different laboratories. The research team investigated four different RCA obtained from longterm outdoor exposure testing performed at CANMET in Ottawa, Ontario, Canada. Prior to his academic position at Université Laval, Dr. Fournier was a researcher at CANMET-MTL and was directly responsible for the casting of the outdoor exposure blocks used in this current project.

\subsection{RCA SOURCES}

Outdoor exposure blocks range in size; however the ones from which RCA for this study came from measured nominally $0.70 \mathrm{~m}$ in length and $0.40 \mathrm{~m}$ in height and width. These blocks were originally produced as part of long-term aggregate reactivity testing and correlation to accelerated laboratory testing; blocks such as these are exposed to typical environmental conditions in outdoor exposure in five sites throughout the United States. Both Drs. Fournier and Ideker have research affiliations with these sites, and these strong research ties enabled the research team to obtain blocks on which testing had already been completed for inclusion in this project. In short, the outdoor exposure blocks were selected for their age, extent of alkali-silica reaction damage (coming from the reactive virgin aggregates originally included in the mixture 
designs), and variation in mineralogy of reactive aggregate type. Two additional RCA sources were obtained from demolished structures on the University of Wyoming campus.

For initial modifications to standard testing procedures, reclaimed concrete from an undergraduate materials course at OSU was used so that the RCA from outdoor exposure blocks (available in limited quantity) was not depleted. Results of testing from this aggregate will only be used to demonstrate modifications to standard laboratory testing (e.g., specific gravity and absorption capacity testing). Table 2.1 below provides details about the various outdoor exposure blocks and corresponding reactive aggregate types that were chosen for this project.

Table 2.1: RCA Sources from Reactive Aggregates from Outdoor Exposure Block Testing

\begin{tabular}{l|l|l|l|l}
\hline $\begin{array}{l}\text { Reactive } \\
\text { Aggregate }\end{array}$ & Mineralogy & $\begin{array}{l}\text { Reactivity } \\
\text { Level Based } \\
\text { on CPT }\end{array}$ & $\begin{array}{l}\text { Expansion/Extent } \\
\text { of Damage }\end{array}$ & $\begin{array}{l}\text { Exposure Site } \\
\text { Location }\end{array}$ \\
\hline Alberta & $\begin{array}{l}\text { Mixed mineralogy } \\
\text { gravel (CA) }\end{array}$ & $\begin{array}{l}\text { Moderately } \\
\text { reactive }\end{array}$ & $\begin{array}{l}0.15-0.25 \% \\
\text { expansion }\end{array}$ & $\begin{array}{l}\text { Ottawa, ON } \\
\text { Canada }\end{array}$ \\
\hline Bernier & $\begin{array}{l}\text { Argillaceous } \\
\text { Limestone (CA) }\end{array}$ & $\begin{array}{l}\text { Highly } \\
\text { reactive }\end{array}$ & $\begin{array}{l}0.15-0.25 \% \\
\text { expansion }\end{array}$ & $\begin{array}{l}\text { Ottawa, ON } \\
\text { Canada }\end{array}$ \\
\hline Potsdam & Sandstone (CA) & $\begin{array}{l}\text { Highly } \\
\text { reactive }\end{array}$ & $\begin{array}{l}0.15-0.25 \% \\
\text { expansion }\end{array}$ & $\begin{array}{l}\text { Ottawa, ON } \\
\text { Canada }\end{array}$ \\
\hline Springhill & Greywacke (CA) & $\begin{array}{l}\text { Very highly } \\
\text { reactive }\end{array}$ & $\begin{array}{l}0.15-0.25 \% \\
\text { expansion }\end{array}$ & $\begin{array}{l}\text { Ottawa, ON } \\
\text { Canada }\end{array}$ \\
\hline UW Steps & $\begin{array}{l}\text { Local sources, } \\
\text { likely Cheyenne }\end{array}$ & $\begin{array}{l}\text { Very highly } \\
\text { reactive }\end{array}$ & $\begin{array}{l}\text { Clear expansion } \\
\text { observed. }\end{array}$ & NA \\
\hline $\begin{array}{l}\text { UW Old Power } \\
\text { Plant }\end{array}$ & Local sources & $\begin{array}{l}\text { Moderately } \\
\text { reactive }\end{array}$ & $\begin{array}{l}\text { Map cracking } \\
\text { observed. }\end{array}$ & NA \\
\hline $\begin{array}{l}\text { OSU Materials } \\
\text { Course RCA }\end{array}$ & $\begin{array}{l}\text { Locally available } \\
\text { river sand and } \\
\text { gravel }\end{array}$ & $\begin{array}{l}\text { Very Highly } \\
\text { Reactive }- \\
\text { FA* }\end{array}$ & $\begin{array}{l}\text { No evidence of } \\
\text { expansion, early-age } \\
\text { concrete }\end{array}$ & NA \\
\hline
\end{tabular}

*reactivity based on ASTM C $1260-A M B T$

In Table 2.1, reactive coarse aggregates are denoted with (CA) and reactive fine aggregates with (FA). In these blocks, a corresponding non-reactive fine or coarse aggregate, respectively, was used to complete the concrete mixture. This is a standard testing procedure prescribed in ASTM C 1293-08b to isolate reactivity of one of the aggregate types. Current ASTM and CSA standards do not allow for combined aggregate testing because it can result in a non-conservative approach when characterizing aggregate reactivity or mitigation measures. It can be seen that the aggregates chosen were either moderately, highly or very highly reactive aggregates based on testing in ASTM C 1293 (Concrete Prism Test - CPT), and were selected once expansions had reached $0.15-0.25 \%$ for the aggregates taken from outdoor exposure blocks in Ottawa and from $0.10-0.30 \%$ for aggregates taken from outdoor exposure blocks in Ottawa. Due to environmental impacts on the block, the number of blocks taken to make enough RCA for testing, the time of placement in the expansion site and the damage level vary. However, this represents a significant amount of control for laboratory-based RCA testing. Certainly testing from stockpiled aggregate would not afford this type of detailed knowledge about the extent of 
damage that had already occurred. Because Phase I, or initial testing, evaluated interlaboratory variability of accelerated testing, it was important to retain as much control as possible over the known state of the recycled concrete aggregates. Future testing should certainly include evaluation of stockpiled RCA as that is what the industry will use.

Once the outdoor exposure blocks had reached a desired level of expansion and damage in the form of cracking from deleterious alkali-silica reaction, the blocks were broken up by mechanical means (jack-hammering, hammer drill and sledge hammers/wedges) to retain nominally $100-150 \mathrm{~mm}$ pieces of RCA. That material was then processed at a pilot-scale crushing operation at CANMET laboratories in Ottawa to obtain material from nominally a half

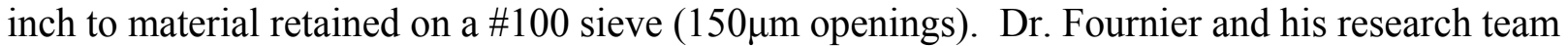
processed and distributed the aggregates to the laboratories in this study for further testing. This would be typical of a large-scale crushing operation for stockpiled RCA as well.

Material, which will herein be referred to as "crusher's fines" RCA, was material that met the size requirements for the accelerated testing methods to be discussed in Section 2.4.1. This material only needed to be sieved into the appropriate size and prepared according to the standard. There was also larger material (a half inch down to \# 4) obtained during the crushing process that had to be "re-crushed" in the respective laboratories with small-scale jaw crushers and pulverizers to meet the size and gradation requirements of accelerated testing methods also to be discussed in Section 2.4. The gradation (e.g., particle size and amount from each size fraction) was identical between crusher's fines and re-crushed coarse. However, compositionally the two RCA sources were suspected to be different as a result of the crushing operations. It was hypothesized that the material captured during large-scale crushing (crusher's fines) contained a higher cement paste content compared to the re-crushed coarse material, likely affecting its reactivity level. Prior research has shown that there is increased paste content in a coarse RCA versus that of a fine RCA due to cement paste loss during crushing, and this can affect the reactivity of the RCA (Shehata et al., 2010). It is important, therefore, to classify the two types of crushing procedures and analyze their effect on the reactivity of the RCA. Figure 2-1 and Figure 2-2 show a picture of the typical jaw crusher and pulverizer used in the laboratory at Oregon State University to further reduce the size of RCA. 


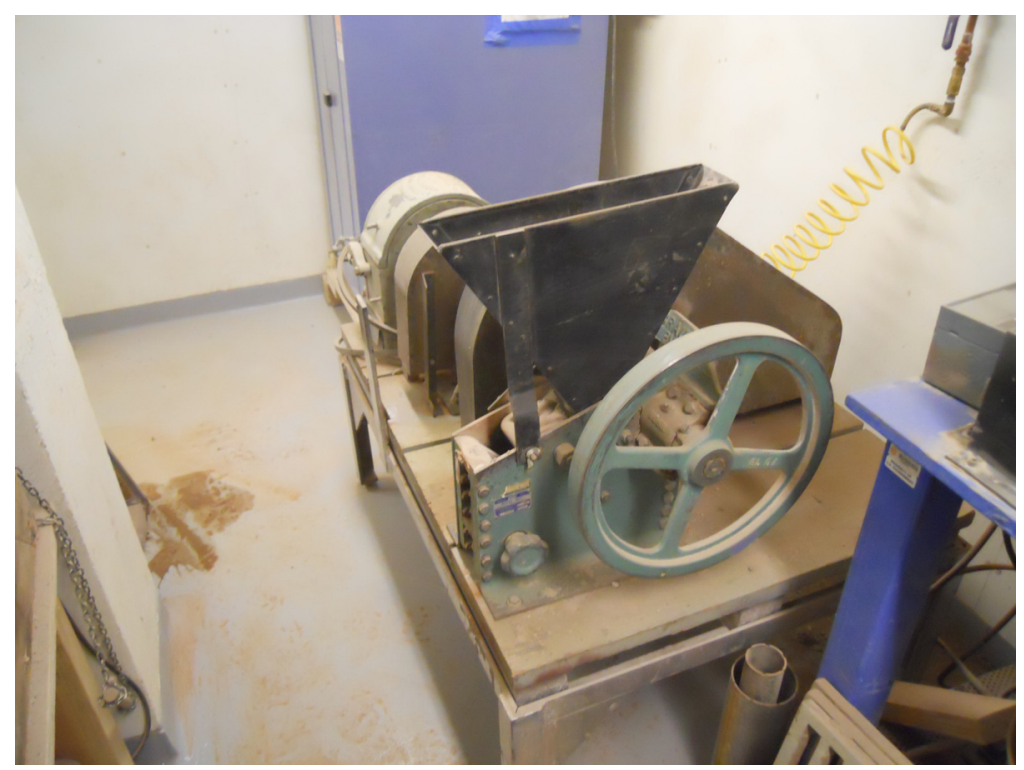

Figure 2-1: Jaw Crusher at Oregon State University

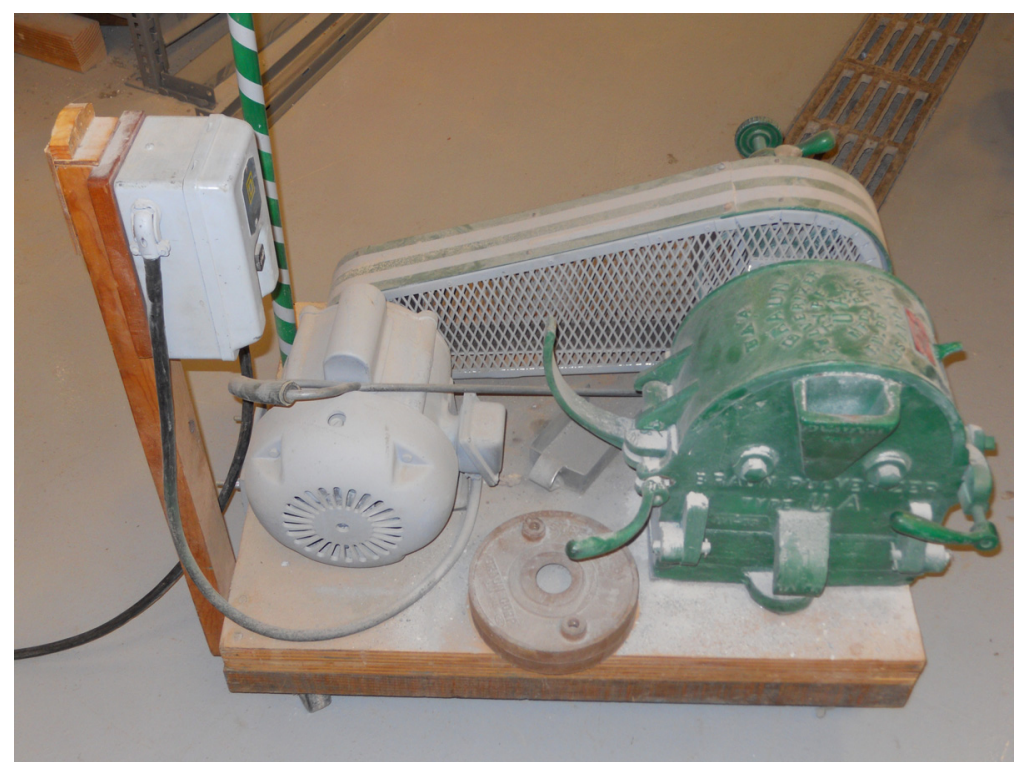

Figure 2-2: Pulverizer at Oregon State University

In addition to the potentially reactive RCA tested in the project, it was necessary to combine RCA in mortar mixtures with nonreactive fine aggregate. Typically, RCA in this project was used as a replacement for virgin aggregate at $25 \%, 50 \%$ and $100 \%$ replacement levels. The nonreactive aggregates used are shown below in Table 2.2. 
Table 2.2: Nonreactive Aggregate Used in Combination with RCA for Laboratory Testing

\begin{tabular}{l|l|l|l|l}
\hline $\begin{array}{l}\text { Nonreactive } \\
\text { Aggregate by } \\
\text { Quarry }\end{array}$ & Mineralogy & $\begin{array}{l}\text { Reactivity } \\
\text { Level Based } \\
\text { on CPT }\end{array}$ & $\begin{array}{l}\text { Expansion/Extent } \\
\text { of Damage }\end{array}$ & $\begin{array}{l}\text { Exposure Site } \\
\text { Location }\end{array}$ \\
\hline $\begin{array}{l}\text { CANMET Non- } \\
\text { reactive sand }\end{array}$ & $\begin{array}{l}\text { Natural granitic } \\
\text { sand }\end{array}$ & Nonreactive & $\begin{array}{l}\text { Exp }<0.04 \% \text { at } 1 \\
\text { year }\end{array}$ & $\begin{array}{l}\text { Ottawa, ON } \\
\text { Canada }\end{array}$ \\
\hline
\end{tabular}

\subsection{CEMENTITIOUS MATERIALS TESTING}

The research team used a single type of cement supplied by CANMET for all of the interlaboratory testing performed in this research study because the main interest was to determine the ability of and reproducibility of results from ASTM C 1260 to properly characterize potential alkali-silica reactivity of RCA. As a result, the only differences were the type of equipment used for testing and the different researchers preparing, monitoring and analyzing samples. All cements were tested for oxide analysis at an independent testing laboratory. Table 2.3 shows the oxide analyses for the cements used in the testing program.

Table 2.3: Cement Oxide Analysis

\begin{tabular}{|c|c|c|c|c|c|}
\hline Oxide & $\begin{array}{l}\text { Oxide } \\
\text { Short }\end{array}$ & $\begin{array}{l}\text { CANMET } \\
\text { Cement }\end{array}$ & $\begin{array}{l}\text { LaFarge I/II, } \\
\text { - OSU } \\
\text { Materials } \\
\text { Course }\end{array}$ & Holcim - UW & $\begin{array}{l}\text { Dakotah - } \\
\text { UW }\end{array}$ \\
\hline Silicon Dioxide & $\mathrm{SiO}_{2}$ & 19.57 & 20.51 & - & 22.36 \\
\hline Aluminum Oxide & $\mathrm{Al}_{2} \mathrm{O}_{3}$ & 4.88 & 4.72 & - & 3.75 \\
\hline Iron Oxide & $\mathrm{Fe}_{2} \mathrm{O}_{3}$ & 2.91 & 3.23 & - & 3.64 \\
\hline $\begin{array}{l}\text { Total }\left(\mathrm{SiO}_{2}+\right. \\
\left.\mathrm{Al}_{2} \mathrm{O}_{3}+\mathrm{Fe}_{2} \mathrm{O}_{3}\right) \\
\end{array}$ & & 27.36 & 28.46 & - & 29.75 \\
\hline Calcium Oxide & $\mathrm{CaO}$ & 60.82 & 64.21 & - & 65.36 \\
\hline Magnesium Oxide & $\mathrm{MgO}$ & 2.52 & 0.80 & - & 1.16 \\
\hline Sodium Oxide & $\mathrm{Na}_{2} \mathrm{O}$ & 0.27 & 0.30 & 0.21 & 0.13 \\
\hline Potassium Oxide & $\mathrm{K}_{2} \mathrm{O}$ & 0.97 & 0.29 & 0.76 & 0.12 \\
\hline Total Alkalies & $\mathrm{Na}_{2} \mathrm{O}$ & 0.91 & 0.49 & 0.71 & 0.19 \\
\hline Titanium Dioxide & $\mathrm{TiO}_{2}$ & - & 0.23 & - & 0.16 \\
\hline $\begin{array}{l}\text { Manganese } \\
\text { Dioxide }\end{array}$ & $\mathrm{MnO}_{2}$ & - & 0.08 & - & 0.03 \\
\hline $\begin{array}{l}\text { Phosphorus } \\
\text { Pentoxide }\end{array}$ & $\mathrm{P}_{2} \mathrm{O}_{5}$ & - & 0.07 & - & 0.09 \\
\hline Strontium Oxide & $\mathrm{SrO}$ & - & 0.17 & - & 0.16 \\
\hline Barium Oxide & $\mathrm{BaO}$ & - & 0.07 & - & 0.03 \\
\hline Sulfur Trioxide & $\mathrm{SO}_{3}$ & 3.32 & 2.7 & - & 1.93 \\
\hline Loss on Ignition & & 2.82 & 2.63 & - & 1.09 \\
\hline Insoluble Residue & & - & 0.21 & - & 0.56 \\
\hline
\end{tabular}




\begin{tabular}{l|l|l|l|l|l}
\hline $\begin{array}{l}\text { Tricalcium } \\
\text { Silicate }\end{array}$ & $\mathrm{C}_{3} \mathrm{~S}$ & - & 61.51 & - & 60.18 \\
\hline $\begin{array}{l}\text { Tricalcium } \\
\text { Aluminate }\end{array}$ & $\mathrm{C}_{3} \mathrm{~A}$ & - & 7.03 & - & 3.79 \\
\hline Dicalcium Silicate & $\mathrm{C}_{2} \mathrm{~S}$ & - & 12.40 & - & 18.72 \\
\hline $\begin{array}{l}\text { Tetracalcium } \\
\text { Aluminoferrite }\end{array}$ & $\mathrm{C}_{4} \mathrm{AF}$ & & 9.84 & - & 11.08 \\
\hline
\end{tabular}

$* \mathrm{TiO}_{2}$ and $\mathrm{P}_{2} \mathrm{O}_{3}$ not included in $\mathrm{Al}_{2} \mathrm{O}_{3}$

The cement used for most of the OSU testing, and all of the interlaboratory testing, was the CANMET cement. One additional cement type was used at OSU for concrete reclaimed from the OSU Materials course, LaFarge Type I/II. At the University of Wyoming, two additional cement types, Holcim and Dakotah, were used for additional testing in Phase II. These cements were of specific interest to determine the influence of cement alkali content on testing results. Thus, this was the only information requested from independent testing.

\subsection{AGGREGATE CHARACTERIZATION-MODIFICATION TO STANDARD METHODS}

Virgin aggregates are typically characterized for standard properties for many types of laboratory testing and field applications. In this research project it was necessary to characterize the RCA, which consists of four main phases: cement paste, fine aggregate, coarse aggregate (whole and fractured), and air voids. The presence of cement paste and especially increased air voids (compared to virgin aggregates) required modification to the following standard testing methodologies:

Absorption capacity (concrete and mortar mixing) - ASTM C 128 Mortar mixing - ASTM C 305

Alkali-silica reaction testing - ASTM C 1260

In the following subsections, a brief overview of the testing methodology and subsequent modifications that were made when testing RCA will be given. Details about standard testing procedures that were not modified can be referred to in the given standard.

\subsubsection{ASTM C 128 - Specific Gravity and Absorption Capacity Testing of Fine Aggregate}

The absorption capacity of an aggregate is the increase in the aggregate's mass due to water in the pores, but not including water adhering to the outside surface of the particles, expressed as a percent of dry mass. In short, the aggregate is soaked for a 24-hour period and then carefully dried back to a condition where the aggregate is saturated, but the surface is dry (e.g., all pores are full of water). This condition is referred to as saturated surface dry or "SSD." The test method is highly subjective and should be performed for a number of replicates to average results. A brief outline of the procedure is provided below. Values obtained during the testing method will give both absorption capacity and specific gravity. 
a) Approximately 1,000 grams of fine aggregate (already saturated) is obtained.

b) Record the mass of the pycnometer (Mason jar and top) in grams when filled with water (B).

c) Spread the sample on a flat surface and stir to obtain uniform drying until the sample approaches a free-flowing condition. Put the partially dried fine aggregate loosely in the clean mold (overfill) and lightly tamp the surface 25 times. Lift the mold vertically. If the fine aggregate just slumps upon removal of the mold, this indicates a saturated surface dry (SSD) condition.

d) Immediately put $500 \pm 10$ grams of the SSD material (S) in the pycnometer.

e) Fill with water to about $90 \%$ capacity. Roll, invert and agitate the pycnometer to eliminate all the air bubbles. Fill the pycnometer to the calibrated level (completely full). Record the mass (C).

f) Dry the sample in the oven at $110^{\circ} \mathrm{C}$. Record the net mass of the sample in grams (A).

Due to the high absorption capacity of RCA compared to virgin aggregates (typically $0.5-4 \%$ by mass of aggregate), it was necessary to determine an appropriate procedure for characterizing the absorption capacity of the various RCA sources in this project. RCA from the OSU Materials course was initially used to determine the proper testing procedure. From laboratory experience with other highly absorptive aggregates (lightweight fine aggregates), it was known that the aggregate may require a longer soaking period to reach full saturation.

A series of soaking periods - 24, 48 and 72 hours - were investigated. It was determined that the RCA reached at least $95 \%$ of its absorption capacity by 24 hours as little appreciable gain in water uptake was observed at 48 and 72 hours. Further testing revealed that a soaking time of 30 minutes was enough to saturate the RCA to $85 \%$ of its total absorption capacity. This soaking time was used in the modified mortar mixing procedure outlined in Section 2.3.2.

\subsubsection{ASTM C 305 - Mortar Mixing Procedure}

ASTM C 305 is the standard procedure for mixing cement pastes and mortars. Generally, the test involves placing the water in the bottom of a $5 \mathrm{~L}$ commercial bakery-type mixer followed by the cement. This soaks for a period for 30 seconds prior to the mixing procedure, which in total takes three minutes from the first contact of water with cement. However, for this testing procedure it was necessary to modify the entire mixing sequence and addition of materials due to the need to pre-soak the materials to reach a point close to SSD prior to mixing.

- After washing and drying the aggregate soak in the mixing water, which is corrected for $100 \%$ of the aggregate absorption, for 30 minutes.

- Mix soaked aggregate for 30 seconds in mixer on low speed (1).

- Slowly add cement over a 30-second period while mixing on low speed (1).

- Stop the mixer and let the mortar stand for one and a half minutes. During the first 15 seconds of this interval, quickly scrape down into the batch any mortar that may have 
collected on the side of the bowl. Then, for the remainder of this interval, cover the bowl with the lid.

- Finish mixing the mortar on medium speed (2) for one minute.

- Finish by casting appropriate specimens for desired testing.

\subsection{ASTM C 1260 GENERAL DESCRIPTION (AMBT)}

ASTM C 1260 is a rapid test used to assess alkali silica reactivity in mortar specimens, and is often referred to as the accelerated mortar bar test (AMBT). This test involves casting mortar prisms that measure $25 \times 25 \times 285 \mathrm{~mm}$. A stainless steel gage stud is cast into both ends of each bar to provide an effective $254 \pm 2.54 \mathrm{~mm}$ gage length. After curing for $24 \pm 2$ hours in $95 \%$ or higher relative humidity, $23 \pm 2{ }^{\circ} \mathrm{C}$ moist room, the specimens are submerged in tap water and placed in a $80 \pm 2^{\circ} \mathrm{C}$ oven where they equilibrate to that temperature before the next reading. The initial or zero reading of the bars is taken $24 \pm 2$ hours later and the bars are quickly transferred to a solution of $1 \mathrm{~N} \mathrm{NaOH}$ which is already at $80 \pm 2^{\circ} \mathrm{C}$. The bars then remain in $1 \mathrm{~N}$ $\mathrm{NaOH}$ at $80 \pm 2^{\circ} \mathrm{F}$ for 14 days. In this project, readings were taken at 21 and 28 days as well. Several measurements are taken throughout this period at approximately the same time each day. Length change is recorded to the nearest 0.0001 inch and results are presented for the average of four prisms to the nearest $0.01 \%$ (ASTM C 1260-07).

It is important to note that this test is only applicable to mortar. Therefore, if the reactivity of a coarse aggregate is to be assessed with this test method, the aggregate must be crushed to meet the gradation standards of the test. As a result, it is possible to expose and remove reactive phases during the crushing, sieving and washing process required by the standard (ASTM C 1260-08). This may lead to inaccurate reactivity predictions when using ASTM C 1260 for field structures containing potentially reactive coarse aggregates (Thomas et al., 2006).

Expansion criteria for this test fall into three categories within ASTM C 1260 based on expansion measured 16 days after casting (14 days after immersion in $1 \mathrm{~N} \mathrm{NaOH}$ ). Expansion of less than $0.10 \%$ is generally considered to be indicative of innocuous behavior. Expansion of more than $0.20 \%$ indicates that the aggregates are potentially deleterious. Expansion that falls between 0.10 and $0.20 \%$ indicates that the aggregate may exhibit either innocuous or deleterious performance in the field (ASTM C 1260-07). The above expansion criteria, as described in ASTM C 1260, are not actually used by many researchers or agencies. Rather, the consensus among many ASR researchers and engineers is to use an expansion limit of $0.10 \%$ after 14 days of immersion in the soak solution to indicate aggregate reactivity (Thomas et. al, 2007).

By ASTM C 1260 standards, aggregates are classified by day 14 as reactive; however, it has been suggested that researchers continue the test for 28 days for further observation (Fournier, 2006). Because the ASTM C 1260 test conditions are harsh, the rate of expansion can increase between 14 and 28 days. This means a specimen may pass within 14 days and fail within 28 days. Such examples contribute to false negative results that are widely reported in the literature. Although ASTM C 1260 does not provide guidance on 28-day measurements for a classification, this speculation may help engineers recommend conservative treatment options. For example, an 
engineer may change the aggregate classification if it reached the $0.1-0.2 \%$ expansion limits at the 28-day point. Other researchers have shown the strongest correlation to field exposure (in outdoor exposure blocks and actual structures) to be a 14-day limit at $0.1 \%$ expansion (Thomas et. al, 2007). For this study's purposes, an expansion limit of $0.10 \%$ at 14 days will be used. However, readings will be taken out to 28 days to provide longer-term expansion data, which will be beneficial to more fully characterize RCA reactivity and for future data analysis should different limits be suggested for RCA.

\subsubsection{Discussion of ASTM C 1260 testing method}

The shortcomings of ASTM C 227 and ASTM C 289 (e.g., excessive leaching in C 227 and aggregate only testing C 289) highlighted the need for and led to the development of ASTM C 1260 (Lane, 1999), also known as the Accelerated Mortar Bar Test (AMBT). In 1986, Oberholster and Davies developed a test in South Africa (Oberholster and Davies, 1986) that eventually became ASTM C 1260 and was formally adopted in 1994.

ASTM C 1260 uses the mortar bars from ASTM C 227 and the soak solution environment from ASTM C 289. The mortar bars are stored in $1 \mathrm{~N} \mathrm{NaOH}$ solution at $80^{\circ} \mathrm{C}$ to accelerate the reaction, and the water/cement ratio is specified at 0.47 . After casting, the bars are stored in a moist curing room for 24 hours. After an initial comparator reading is taken, the bars are immersed in tap water at $80^{\circ} \mathrm{C}$ for 24 hours. The mortar bars are then placed in the $\mathrm{NaOH}$ solution at $80^{\circ} \mathrm{C}$ and measured periodically over the next 14 days. A 14-day expansion of less than $0.10 \%$ indicates an innocuous aggregate, and expansion greater than $0.20 \%$ indicates a potentially deleteriously reactive aggregate. Expansion between $0.10 \%$ and $0.20 \%$ can include "aggregates that are known to be both innocuous and deleterious in field performance" (ASTM C 1260 2010).

ASTM C 1260 is preferred to other tests because it is reliable and quick, and the severe testing environment helps to identify more slowly reacting aggregates (ACI 2008). Unfortunately, the test does have limitations. The harsh testing environment does not represent actual field conditions, and some aggregates that perform well in the field actually fail this test. Therefore, ASTM C 1260 should not be solely used to reject aggregate. Other tests such as ASTM C 33 (2003) or ASTM C 1293 are also used (Touma et al., 2001). ASTM C 1293 has been shown, though rarely, to classify an aggregate as nonreactive when it proves to be reactive in the field (Fournier et al., 2006).

\subsubsection{Testing program}

The RCA used in this research came from large concrete block specimens exposed to the outdoors in Ottawa. These blocks displayed expansions from ASR in the field. The blocks were crushed and samples distributed to the four participating universities. Four types of RCA were reviewed: Bernier, Potsdam, Alberta and Springhill.

The authors wanted to observe the effect of different replacement percentages of RCA for nonreactive aggregate. Each university laboratory performed tests separately on the crusher's fines and the re-crushed coarse RCA for a total of two groups of specimens. 
Specimens with 100\% RCA, 50\% RCA and 25\% RCA were cast for both the crusher's fines and re-crushed coarse RCA; the remaining percentage of material was nonreactive sand. In some cases, duplicate specimens were cast to compare within laboratory results.

Table 2.4 shows the number of specimen sets for each mixture of re-crushed coarse aggregate, while Table 2.5 shows the required number of specimen sets for each mixture of crusher's fines. Table 2.6 shows the material requirements for each sieve size for the $25 \%, 50 \%$ and $100 \%$ mixtures.

Table 2.4: Number of Specimen Sets for Each Crushed Coarse Aggregate Proportion

\begin{tabular}{l|c|c|c|c}
\hline Mixture Type & \multicolumn{1}{|l|}{ Potsdam } & Springhill & Bernier & Alberta \\
\hline $100 \%$ RCA & 1 & $2+1$ & 1 & 1 \\
\hline $50 \%$ RCA & 1 & 1 & 2 & 2 \\
\hline $25 \%$ RCA & 1 & 1 & 1 & 2 \\
\hline
\end{tabular}

Table 2.5: Required Number of Specimen Sets for Each Crusher's Fines Proportion

\begin{tabular}{l|c|c|c|c}
\hline Mixture Type & Potsdam & Springhill & Bernier & Alberta \\
\hline $100 \%$ RCA & 1 & 2 & 1 & 1 \\
\hline $50 \%$ RCA & 1 & 1 & 2 & 2 \\
\hline $25 \%$ RCA & 1 & 1 & 1 & 2 \\
\hline
\end{tabular}

Table 2.6: Aggregate Material Requirements for Various Proportions in the Study

\begin{tabular}{|c|c|c|c|c|c|}
\hline $\begin{array}{l}\text { Mixture } \\
\text { Type } \rightarrow\end{array}$ & $\begin{array}{l}\text { 100\% RCA } \\
\text { Specimen Type }\end{array}$ & $50 \%$ RCA S & ecimen Type & $25 \%$ RCA S & ecimen Type \\
\hline Sieve Size & $100 \% \mathrm{RCA}(\mathrm{g})$ & $50 \%$ RCA (g) & $\begin{array}{l}50 \% \\
\text { Nonreactive } \\
\text { Sand }(\mathrm{g})\end{array}$ & $25 \%$ RCA (g) & $\begin{array}{l}75 \% \\
\text { Nonreactive } \\
\text { Sand }(\mathrm{g})\end{array}$ \\
\hline No. 8 & 99 & 49.5 & 49.5 & 24.7 & 74.3 \\
\hline No. 16 & 247.5 & 123.8 & 123.8 & 61.9 & 185.6 \\
\hline No. 30 & 247.5 & 123.8 & 123.8 & 61.9 & 185.6 \\
\hline No. 50 & 247.5 & 123.8 & 123.8 & 61.9 & 185.6 \\
\hline No. 100 & 148.5 & 74.2 & 74.2 & 37.1 & 185.6 \\
\hline Total $(\mathrm{g})$ & 990 & 495.1 & 495.1 & 247.5 & 742.5 \\
\hline
\end{tabular}

\subsubsection{Modifications to ASTM C 1260 Test Method - RCA Washing}

Section 7.2 of the ASTM C 1260 test method requires that the aggregates be sieved into separate gradations to meet the specific grading of the standard. Following the sieving procedure, the 
aggregates are washed over a finer screen size than that gradation until the water runs clear. An issue that the research team encountered was that when following this procedure for RCA using the OSU Materials course, the water never ran clear. This was of concern as the washing procedure may be further eroding the cement paste, hydrating it or leaching out constituents such as calcium and alkalies from the RCA. However, work by Shehata demonstrated that long soak periods (e.g., up to 18 hours) in water and excessive washing of RCA had insignificant effects on long-term expansion and damage from ASR. For an unwashed RCA, the expansion at two years in ASTM C 1293 was $0.066 \%$ compared to $0.061 \%$ for washed RCA (Shehata, 2010).

Therefore a modified procedure for washing the aggregate was used. That is outlined below:

- Sieve aggregate.

- Keep aggregate in separate sieve size.

- Use this quantity of aggregate: $1500 \mathrm{~g}$ at a time.

- Wash aggregate using garden hose with a fanned spray hose nozzle.

- Wash aggregate trying to obtain a clear water runoff.

- Clear runoff is hard to obtain with RCA. Therefore, different amounts of time per sieve size were allotted to try and obtain, as closely as possible, clear runoff.

- Sieve \#8 = three and a half minutes;

- Sieve $\# 16$ = five minutes;

○ Sieve $\# 30$ = six minutes;

- Sieve $\# 50$ = seven minutes; and,

- Sieve $\# 100$ = eight minutes.

This same procedure was used by all of the research laboratories testing RCA in this project. This modification would need to be incorporated into a modified version of the ASTM C 1260 standard for assessing potential alkali-silica reactivity of RCA.

\subsubsection{Modifications to ASTM C 1260 Test Method - Crusher's Fines}

The crusher's fines were observed to have considerable inclusion of wood chips due to the apparatus used for crushing at CANMET. A procedure to remove the wood chips was devised and used at all of the laboratories testing the four RCA sources. This procedure is outlined below:

- Fill 19 liter bucket halfway with water.

- Slowly pour aggregate (one-fourth of total crusher's fine) at a time.

- Stir and let the aggregate settle at the bottom.

- Skim (using a ladle) floating pieces of wood chips.

- Repeat until all the aggregate has been poured.

- Let sit for two minutes.

- Stir aggregate.

- Let sit for one minute.

- Skim remaining pieces of wood chips. 
- Decant extra water.

- Dry back for sieving, processing etc. 


\subsection{AMBT}

\subsection{PHASE I: INTERLABORATORY STUDY}

One of the main goals for this research was to determine whether ASTM C 1260 can reliably detect ASR in recycled concrete aggregates. The testing program began with a comprehensive interlaboratory study among four universities with active research programs in materials testing: Oregon State University (OSU), University of Wyoming (UW), Laval Université (LU), and Ryerson University (RU). The first two schools are part of the OTREC study. Participation by the other two universities was completely voluntary as all four schools realized the significant synergy by working together on this project.

For the purposes of this study, an expansion limit of $0.10 \%$ at 14 days will be used for all AMBT results. However, readings will be taken out to 28 days to provide longer-term expansion data, which will be beneficial to more fully characterize RCA reactivity and for future data analysis should different limits be suggested for RCA.

\subsubsection{Test Results and Discussion}

The UW's results for ASTM C 1260 testing for re-crushed coarse RCA and crusher's fines are shown in Figure 3-1 and Figure 3-2. 


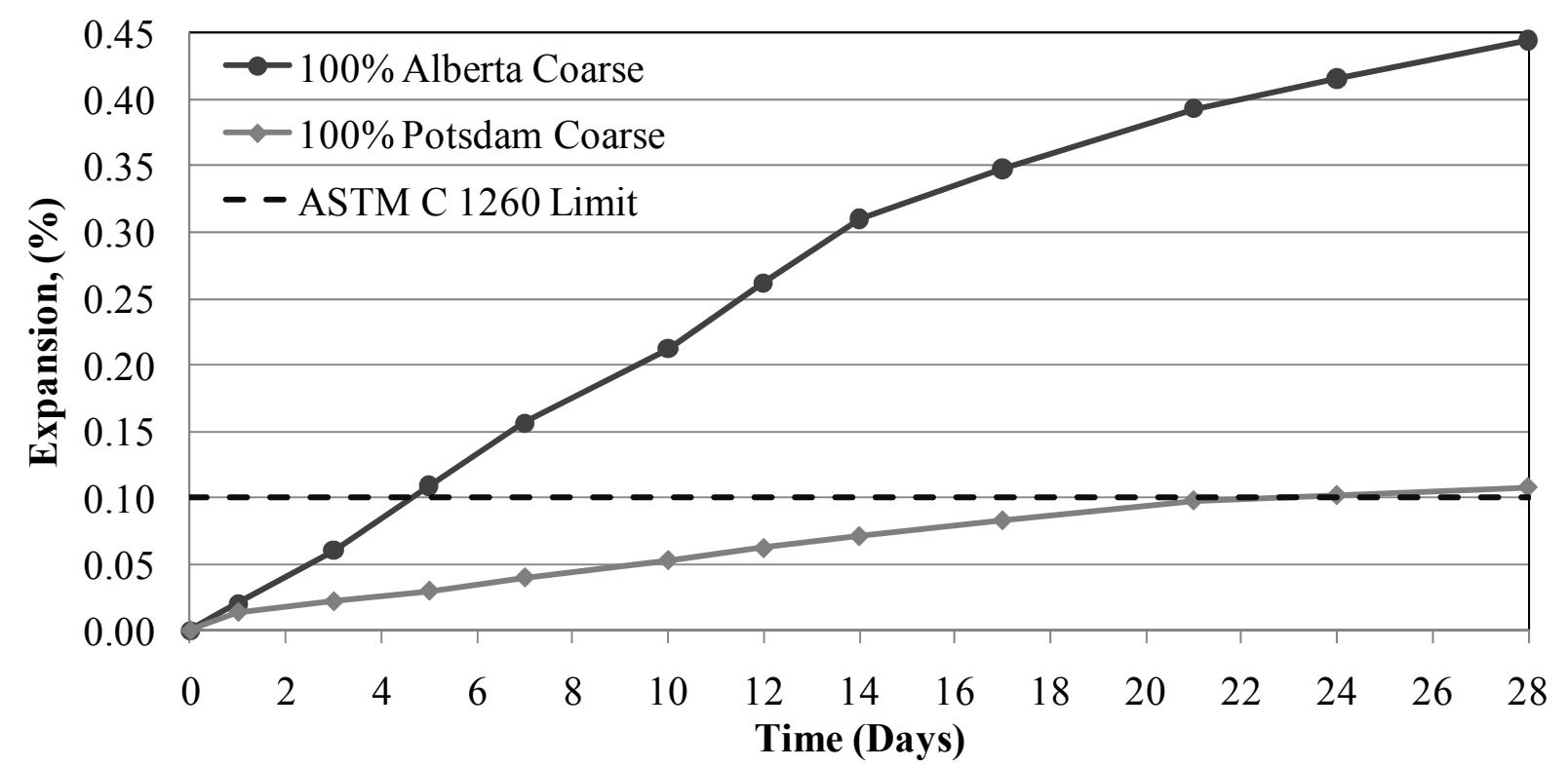

Figure 3-1: Expansion from 0 to 28 days for 100\% Potsdam and 100\% Alberta Re-crushed Coarse RCA

Figure 3-1 shows the expansion of mortar specimens up to day 28 for $100 \%$ Alberta and 100\% Potsdam re-crushed coarse RCA. By day 14, Alberta re-crushed coarse RCA exceeds $0.10 \%$ expansion and would therefore is classified as a reactive aggregate by ASTM C 1260. This figure also shows that by day 14 , Potsdam re-crushed coarse RCA does not reach $0.1 \%$ expansion, which would classify it as a nonreactive aggregate by C 1260.

Measurements taken at day 28 do not change the outcome of the Alberta RCA as it was classified as reactive at 14 days. However, it is clear that a higher level of mitigation would be needed to reduce the reactivity of $100 \%$ Alberta RCA compared to $100 \%$ Potsdam RCA. While Potsdam RCA was classified as nonreactive after 14 days, a level of expansion exceeding $0.10 \%$ at 14 days was exceeded. This may be indicative of a low level of ASR-related expansion due to the reactivity of this aggregate.

Figure 3-2 shows UW expansion curves from day 0 to day 28 for $100 \%$ Alberta and $100 \%$ Potsdam crusher's fines. By day 14, Alberta crusher's fines exceed $0.10 \%$ expansion and were classified as a potentially reactive aggregate by ASTM C 1260. While Potsdam RCA was classified as nonreactive after 14 days, it showed a low level of expansion exceeding $0.10 \%$ at 28 days. 


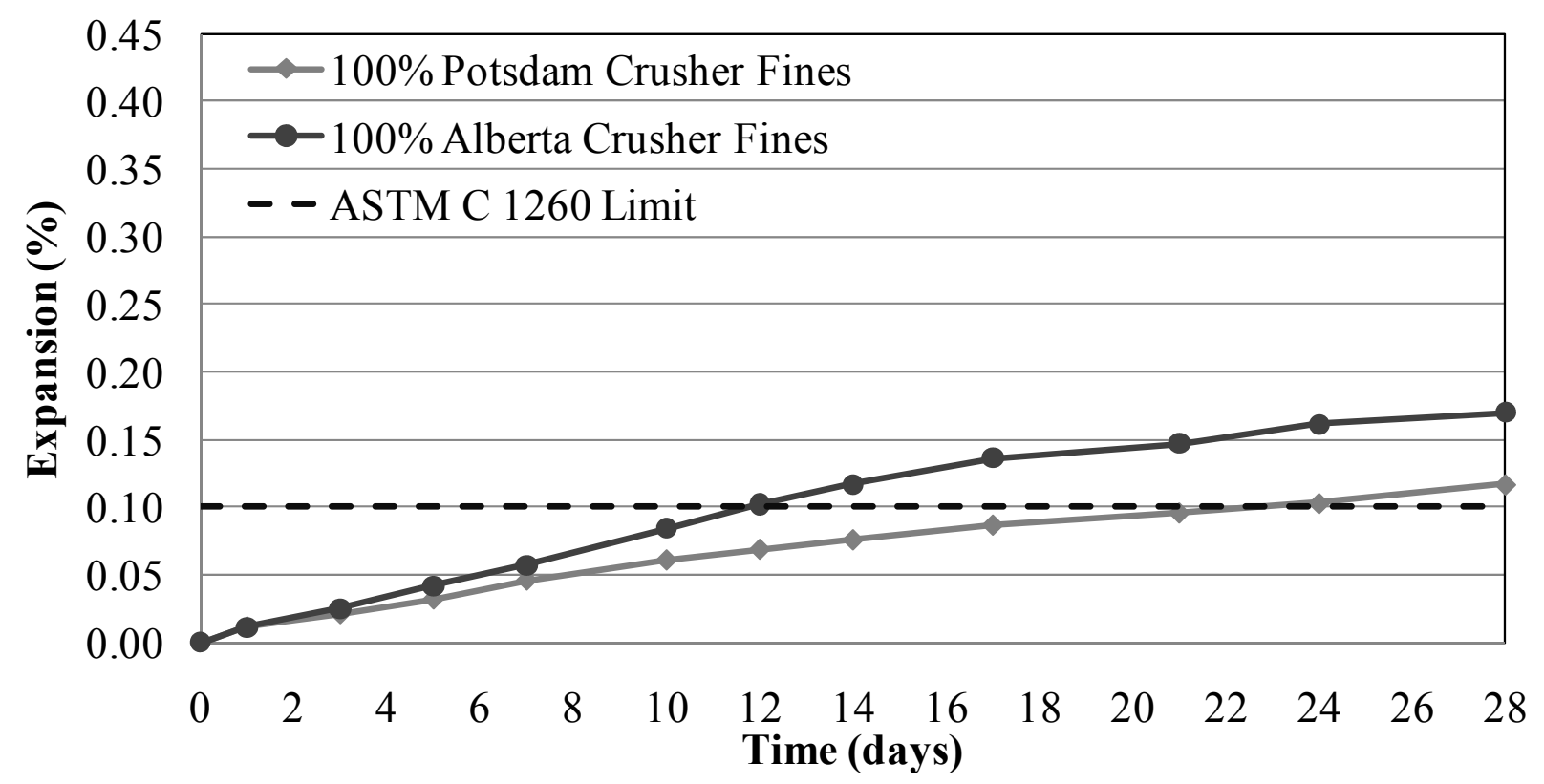

Figure 3-2: Expansion from 0 to 28 days for 100\% Potsdam and 100\% Alberta Crusher's Fines

Complete results from all RCA testing in the AMBT for individual university laboratories are shown in Appendix 8.1. Representative graphs of expansion at 14 days for a $50 \%$ replacement of each of the four RCA tested in all four university laboratories are shown in Figure 3-3 through Figure 3-6. 


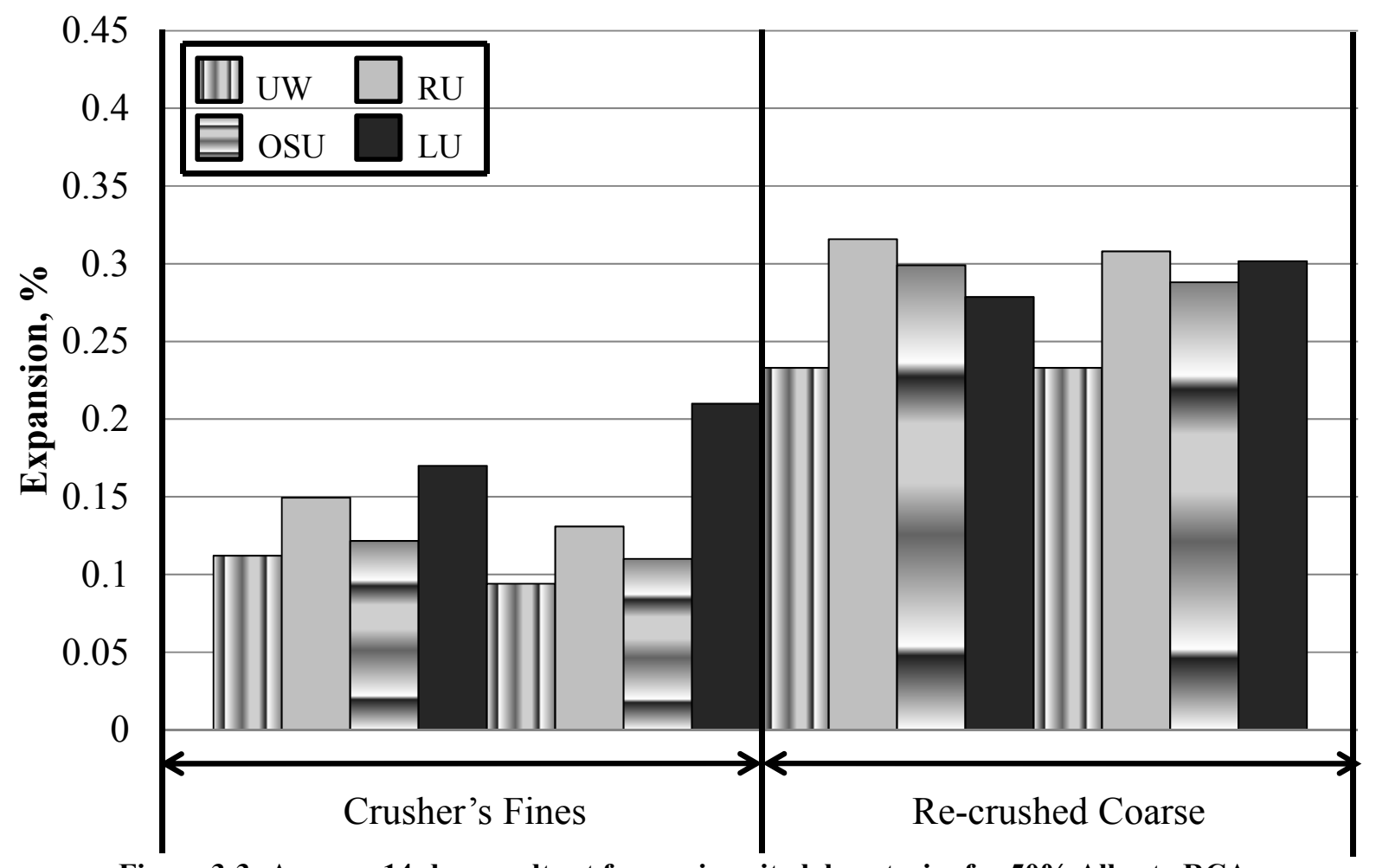

Figure 3-3: Average 14-day results at four university laboratories for 50\% Alberta RCA

Figure 3-3 shows 50\% Alberta 14-day results for both crusher's fines and re-crushed coarse RCA. Keep in mind that the crusher's fines and re-crushed coarse RCA have the same particle size and gradation to meet ASTM C 1260 requirements. However, the two materials are compositionally different as evidenced by the difference in expansion results. Overall, Alberta re-crushed coarse RCA showed a general increase in expansion over crusher's fines for all four universities. UW crusher's fines exhibited the lowest expansions while LU and RU specimens exhibited the highest. Re-crushed coarse RCA LU specimens displayed the highest expansions while UW specimens displayed the lowest. 


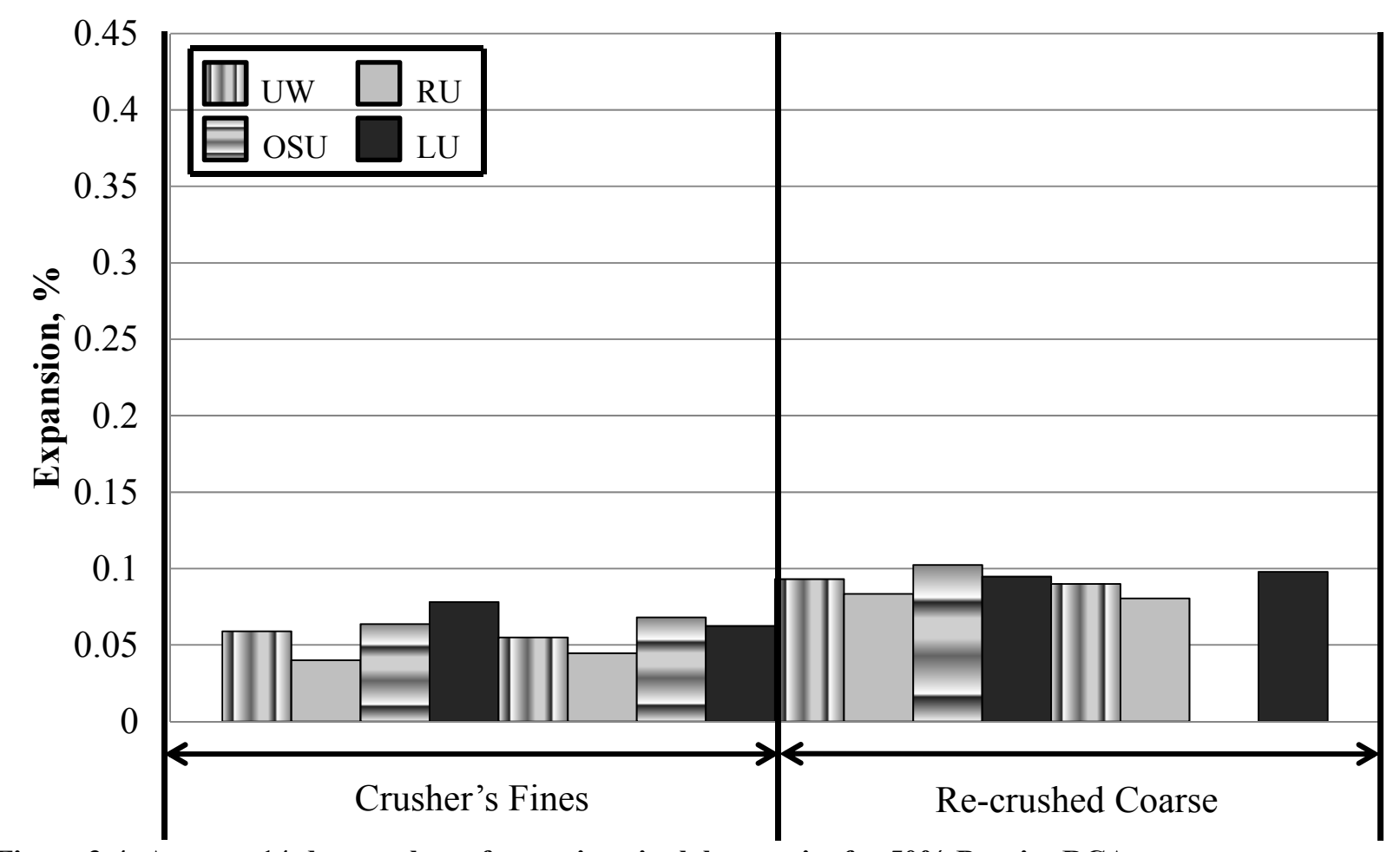

Figure 3-4: Average 14-day results at four university laboratories for 50\% Bernier RCA

Figure 3-4 shows 50\% Bernier 14-day results for crusher's fines and re-crushed coarse RCA. Recrushed coarse RCA showed a general increase in expansion over crusher's fines for all four universities. Overall, LU specimens exhibited the highest expansions for both crusher's fines and re-crushed coarse RCA, while RU specimens exhibited the lowest. OSU did not produce a second $50 \%$ Bernier re-crushed coarse RCA specimen. 


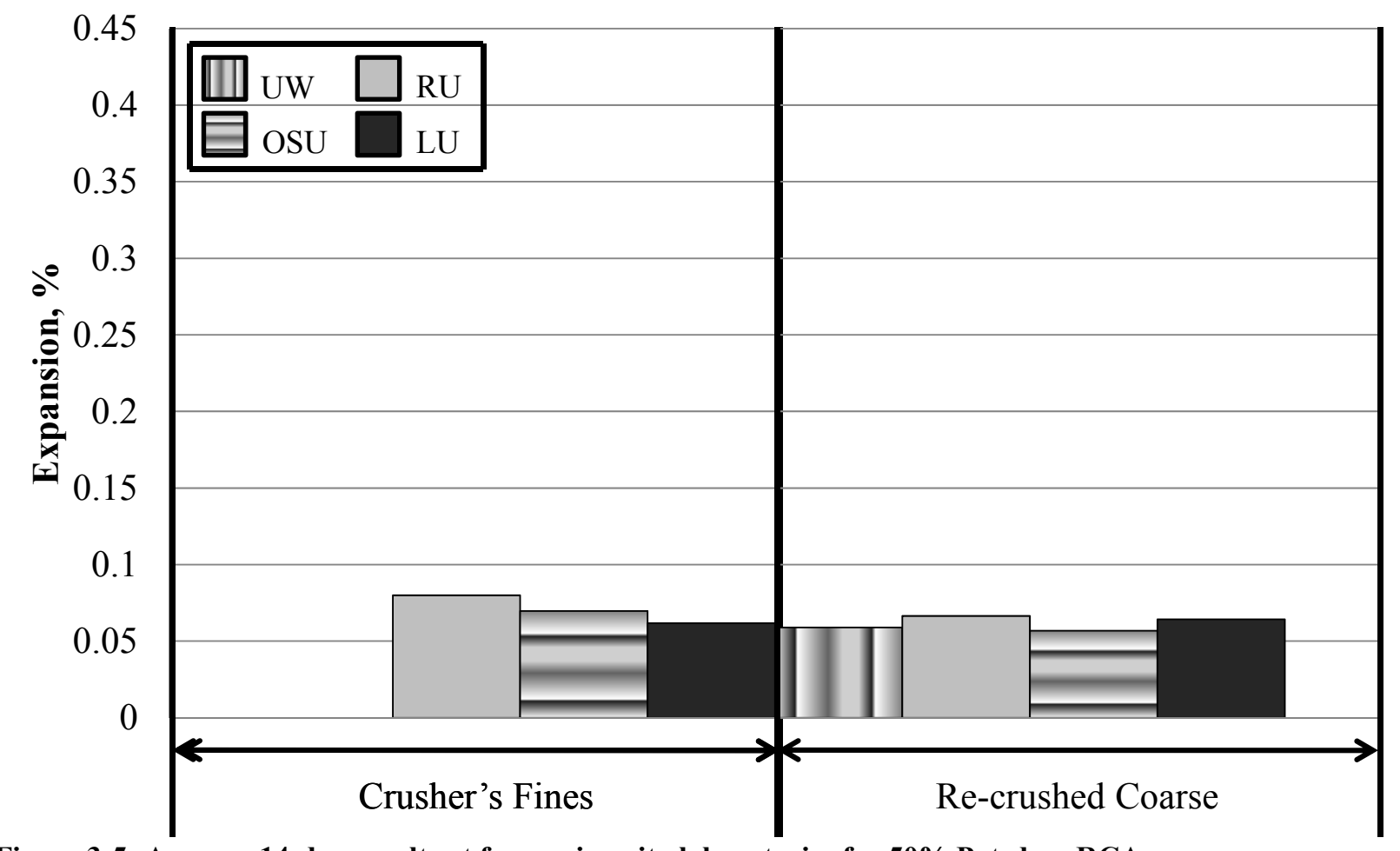

Figure 3-5: Average 14-day results at four university laboratories for 50\% Potsdam RCA

Figure 3-5 shows 50\% Potsdam 14-day results for both crusher's fines and re-crushed coarse RCA. Re-crushed coarse RCA did not show a general increase in expansion over crusher's fines for all four universities. Overall, RU specimens exhibited the highest expansions for both crusher's fines and re-crushed coarse RCA. LU specimens exhibited the lowest expansions among crusher's fines, and UW specimens displayed the lowest re-crushed coarse RCA expansions. UW did not produce a 50\% Potsdam crusher's fines specimen. 


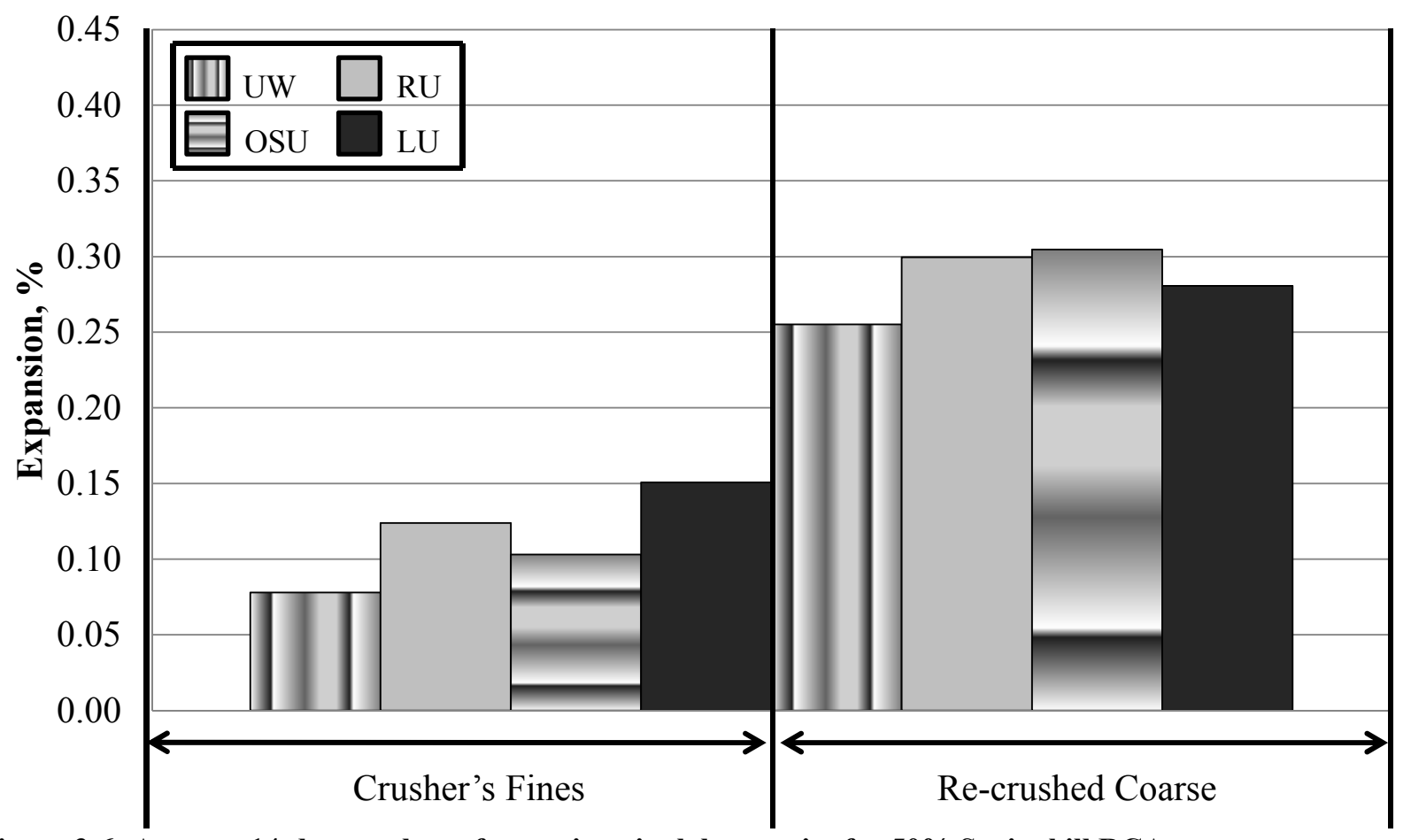

Figure 3-6: Average 14-day results at four university laboratories for $\mathbf{5 0 \%}$ Springhill RCA

Figure 3-6 shows 50\% Springhill 14-day results for both crusher's fines and re-crushed coarse RCA. Re-crushed coarse RCA did show a general increase in expansion over crusher's fines for all four universities. LU specimens exhibited the highest expansions for crusher's fines while UW specimens exhibited the lowest expansions. Among re-crushed coarse RCA, OSU specimens exhibited the highest expansions, while UW specimens displayed the lowest expansions. In summary, for each of the RCA types, all but Potsdam displayed a general increase in expansion at 14 days from crusher's fines to re-crushed coarse RCA.

More variability was expected in crusher's fine results due to the manner in which RCA breaks down. When recycled material is crushed for the first time, breakage occurs at the weakest and preferred fracture planes in the concrete microstructure. Fracture may be further exacerbated by existing damage such as alkali-silica reaction, which was already in process for all four RCA sources presented in this study. Further, for particularly strong virgin aggregates, breakage during crushing occurs along the cement-aggregate bond joints, resulting in crusher's fines that contain proportionally more cement paste than virgin aggregate. Evidence of uneven distribution between crusher's fines and re-crushed coarse RCA is visible in the Springhill results. For all participating laboratories, Springhill re-crushed coarse expansions were two to three times higher than Springhill crusher's fines expansions.

Some weaker virgin aggregates break down easily during initial crushing, causing a more homogeneous physical make up between the first and subsequent crushing. It also causes less variability between crusher's fine and re-crushed coarse aggregate results. Evidence of this 
equitable distribution between re-crushed coarse RCA and crusher's fines is visible in the Bernier and Potsdam results. This is because expansions between re-crushed coarse RCA and crusher's fine specimens were consistent with each other for all proportions tested. Further petrographic examination and microscopic investigation is merited to corroborate these results.

\subsubsection{Summary and Discussion of Results}

Figure 3-7 shows the average 14-day expansion for each of the re-crushed coarse RCA proportions.

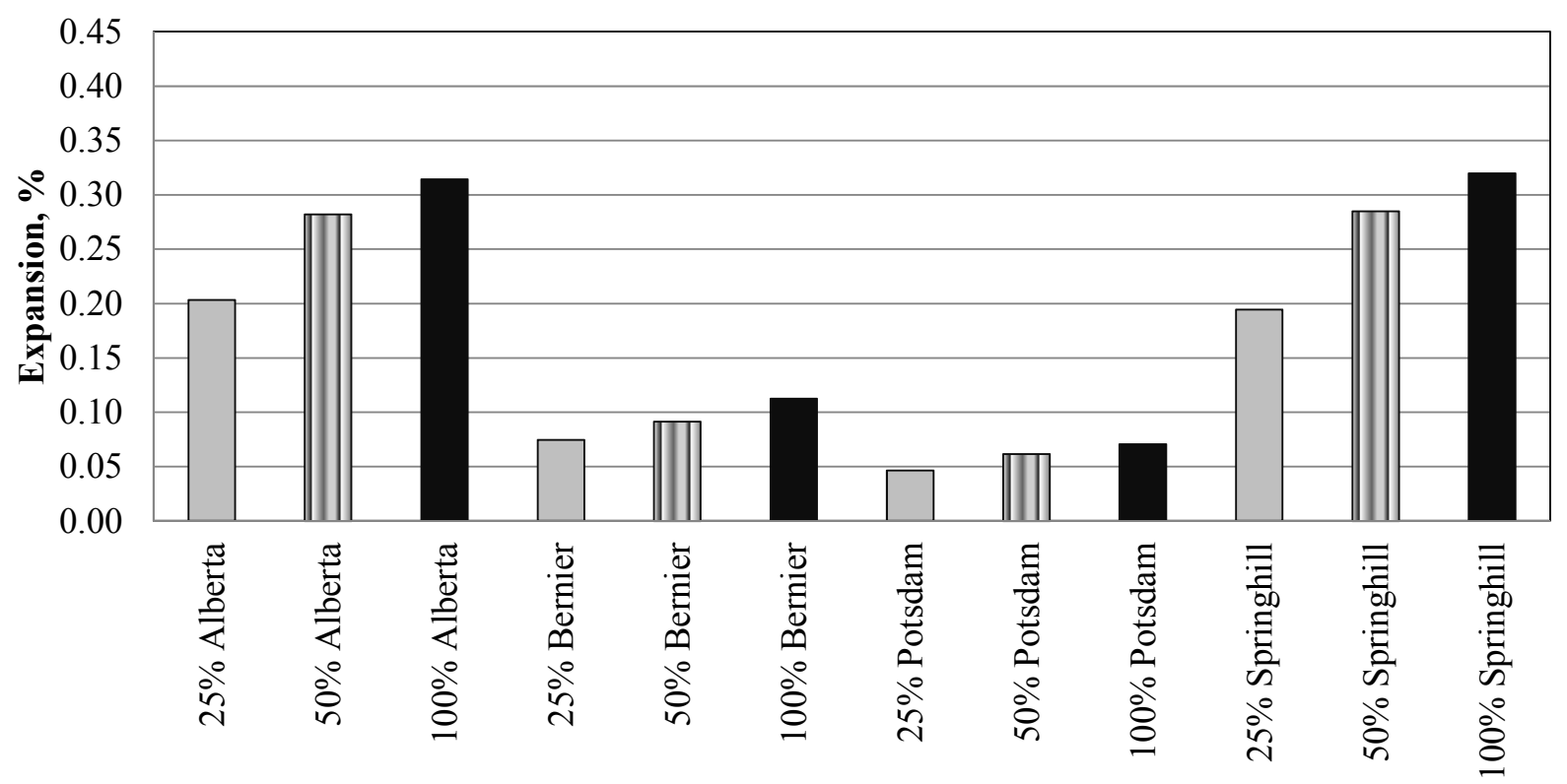

Figure 3-7: Average expansion of 14-day results for re-crushed coarse RCA proportions

For each of the RCA types, the 25\% RCA mixtures showed the lowest average expansion while the $100 \%$ RCA mixture displayed the highest. Overall, Alberta showed the highest average expansions for all three proportions, while Potsdam displayed the lowest average expansions. 


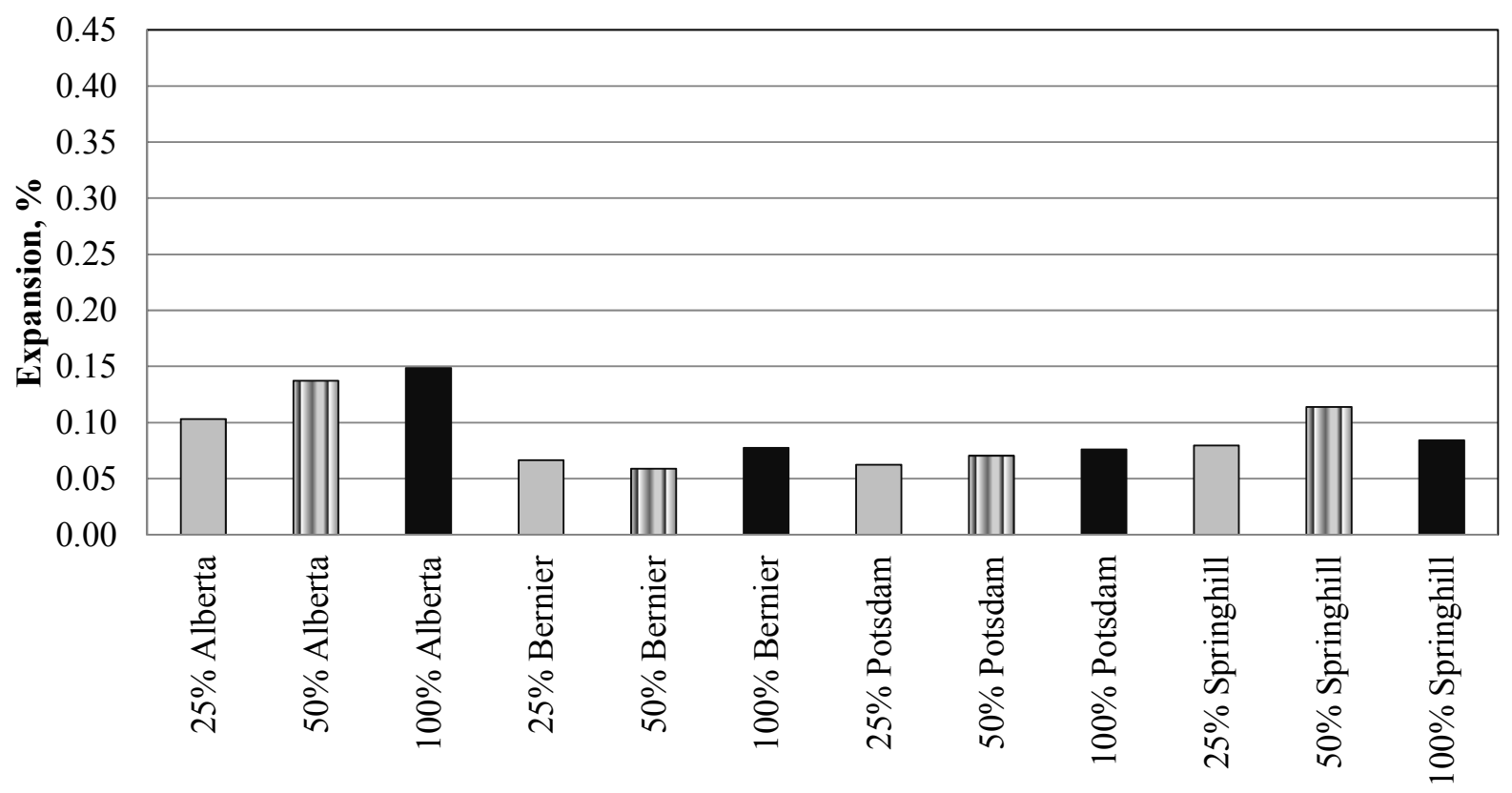

Figure 3-8: Average expansion of 14-day results for crusher's fines

Figure 3-8 shows average 14-day expansions for each crusher's fines proportion. All aggregates have higher expansions at 100\% RCA than for 25\% RCA. Results for Alberta and Potsdam increase as the percentage of RCA increases; while, expansions for 50\% RCA for Bernier and Springhill do not fall between expansions of $25 \%$ and $100 \%$ RCA. No overall trends are apparent.

\subsubsection{Laboratory Variation}

ASTM C 1260 provides guidance on the variation of results for an individual laboratory and multi-laboratory testing. According to ASTM C 1260 (2010), the average multi-laboratory coefficient of variation for materials with an average expansion greater than $0.10 \%$ at 14 days is $15.2 \%$. In addition, the results of two properly conducted aggregate specimen tests in different laboratories should not differ by more than $43 \%$. Both of these criteria were considered when comparing results for a given aggregate replacement level, and acceptable ranges for each of the RCA mixtures are shown in Table 3.1. 
Table 3.1: ASTM Averages and Precision for crushers fines RCA

\begin{tabular}{|c|c|c|c|c|c|c|c|}
\hline \multirow{2}{*}{$\begin{array}{c}\text { RCA Aggregate } \\
\text { Type and } \\
\text { Replacement Level }\end{array}$} & \multirow{2}{*}{$\begin{array}{l}\text { Number of } \\
\text { Samples } \\
\text { (Bars) }\end{array}$} & \multirow{2}{*}{$\begin{array}{c}\text { Average } \\
\text { Expansion } \\
(\%)\end{array}$} & \multirow{2}{*}{ STDEV } & \multirow{2}{*}{$\begin{array}{c}\text { COV } \\
(\%)\end{array}$} & \multicolumn{3}{|c|}{$\begin{array}{l}\text { Precision Boundary Limits }(21.5 \% \\
\text { Above or Below Average Expansion }\end{array}$} \\
\hline & & & & & $\begin{array}{c}\text { Lower } \\
\text { Expansion } \\
\text { Boundary (\%) }\end{array}$ & \begin{tabular}{|c|} 
Upper \\
Expansion \\
Boundary (\%)
\end{tabular} & $\begin{array}{l}\text { Number } \\
\text { of } \\
\text { Outliers }\end{array}$ \\
\hline $25 \%$ Alberta & 24 & 0.103 & 0.0196 & $19.0 \%$ & 0.081 & 0.125 & 6 \\
\hline $50 \%$ Alberta & 24 & 0.137 & 0.0379 & $27.6 \%$ & 0.108 & 0.167 & 7 \\
\hline $100 \%$ Alberta & 12 & 0.149 & 0.0314 & $21.1 \%$ & 0.117 & 0.181 & 5 \\
\hline $25 \%$ Bernier & 12 & 0.066 & 0.0136 & $20.5 \%$ & 0.052 & 0.081 & 3 \\
\hline $50 \%$ Bernier & 24 & 0.059 & 0.0123 & $21.0 \%$ & 0.046 & 0.071 & 5 \\
\hline $100 \%$ Bernier & 12 & 0.077 & 0.0131 & $16.9 \%$ & 0.061 & 0.094 & 2 \\
\hline $25 \%$ Potsdam & 12 & 0.062 & 0.0143 & $22.9 \%$ & 0.049 & 0.076 & 6 \\
\hline $50 \%$ Potsdam & 9 & 0.070 & 0.0092 & $13.1 \%$ & 0.055 & 0.086 & 0 \\
\hline $100 \%$ Potsdam & 12 & 0.076 & 0.0082 & $10.8 \%$ & 0.060 & 0.092 & 0 \\
\hline 25\% Springhill & 12 & 0.080 & 0.0177 & $22.2 \%$ & 0.063 & 0.097 & 5 \\
\hline $50 \%$ Springhill & 12 & 0.114 & 0.0308 & $27.1 \%$ & 0.089 & 0.138 & 5 \\
\hline 100\% Springhill & 21 & 0.084 & 0.0229 & $27.3 \%$ & 0.066 & 0.102 & 11 \\
\hline
\end{tabular}

Among crushers fines RCA samples, only Potsdam 50\% and Potsdam 100\% resulted in a coefficient of variation that conformed to the ASTM C 1260 precision limit of $15.2 \%$ for multilaboratory results.

Table 3.2 displays the number of specimens, the averages, and ASTM precision for each RCA type and proportion of re-crushed coarse RCA. None of the crusher's fines mixtures resulted in a coefficient of variation that conformed to the ASTM precision limit of $15.2 \%$ for multilaboratory results. 
Table 3.2: ASTM Averages and Precision for Re-Crushed Coarse RCA

\begin{tabular}{|c|c|c|c|c|c|c|c|}
\hline $\begin{array}{c}\text { RCA Aggregate } \\
\text { Type and } \\
\text { Replacement } \\
\text { Level }\end{array}$ & $\begin{array}{c}\text { Number } \\
\text { of } \\
\text { Samples } \\
\text { (Bars) }\end{array}$ & $\begin{array}{c}\text { Average } \\
\text { Expansion (\%) }\end{array}$ & STDEV & COV & & \multicolumn{3}{|c|}{$\begin{array}{c}\text { Precision Boundary Limits (21.5\% } \\
\text { Above or Below Average } \\
\text { Expansion }\end{array}$} \\
\cline { 5 - 8 } & & & & & $\begin{array}{c}\text { ASTM Lower } \\
\text { Limit }\end{array}$ & $\begin{array}{c}\text { ASTM } \\
\text { Higher } \\
\text { Limit }\end{array}$ & $\begin{array}{c}\text { Number } \\
\text { of } \\
\text { Outliers }\end{array}$ \\
\hline $25 \%$ Alberta & 24 & 0.203 & 0.0234 & $11.5 \%$ & 0.160 & 0.247 & 0 \\
\hline $50 \%$ Alberta & 24 & 0.282 & 0.0324 & $11.5 \%$ & 0.221 & 0.343 & 0 \\
\hline $100 \%$ Alberta & 12 & 0.314 & 0.0183 & $5.81 \%$ & 0.247 & 0.382 & 0 \\
\hline $25 \%$ Bernier & 12 & 0.075 & 0.0170 & $22.7 \%$ & 0.059 & 0.091 & 4 \\
\hline $50 \%$ Bernier & 21 & 0.091 & 0.0077 & $8.46 \%$ & 0.072 & 0.111 & 0 \\
\hline $100 \%$ Bernier & 12 & 0.113 & 0.0197 & $17.5 \%$ & 0.088 & 0.137 & 1 \\
\hline $25 \%$ Potsdam & 12 & 0.046 & 0.0127 & $27.5 \%$ & 0.036 & 0.056 & 4 \\
\hline $50 \%$ Potsdam & 12 & 0.062 & 0.0045 & $7.33 \%$ & 0.048 & 0.075 & 0 \\
\hline $100 \%$ Potsdam & 12 & 0.071 & 0.0073 & $10.4 \%$ & 0.056 & 0.086 & 0 \\
\hline $25 \%$ Springhill & 12 & 0.195 & 0.0321 & $16.5 \%$ & 0.153 & 0.236 & 3 \\
\hline $50 \%$ Springhill & 12 & 0.285 & 0.0225 & $7.90 \%$ & 0.224 & 0.346 & 0 \\
\hline $100 \%$ Springhill & 21 & 0.320 & 0.0646 & $20.2 \%$ & 0.251 & 0.388 & 5 \\
\hline
\end{tabular}

A graphical representation of these values can be seen in Figure 3.9 and Figure 3.10 These graphs show the 14-day expansion averages and ASTM precision limits with the coefficients of variation in percentages above each mixture expansion value for each RCA type and proportion of crusher's fines and re-crushed coarse RCAs, respectively. 


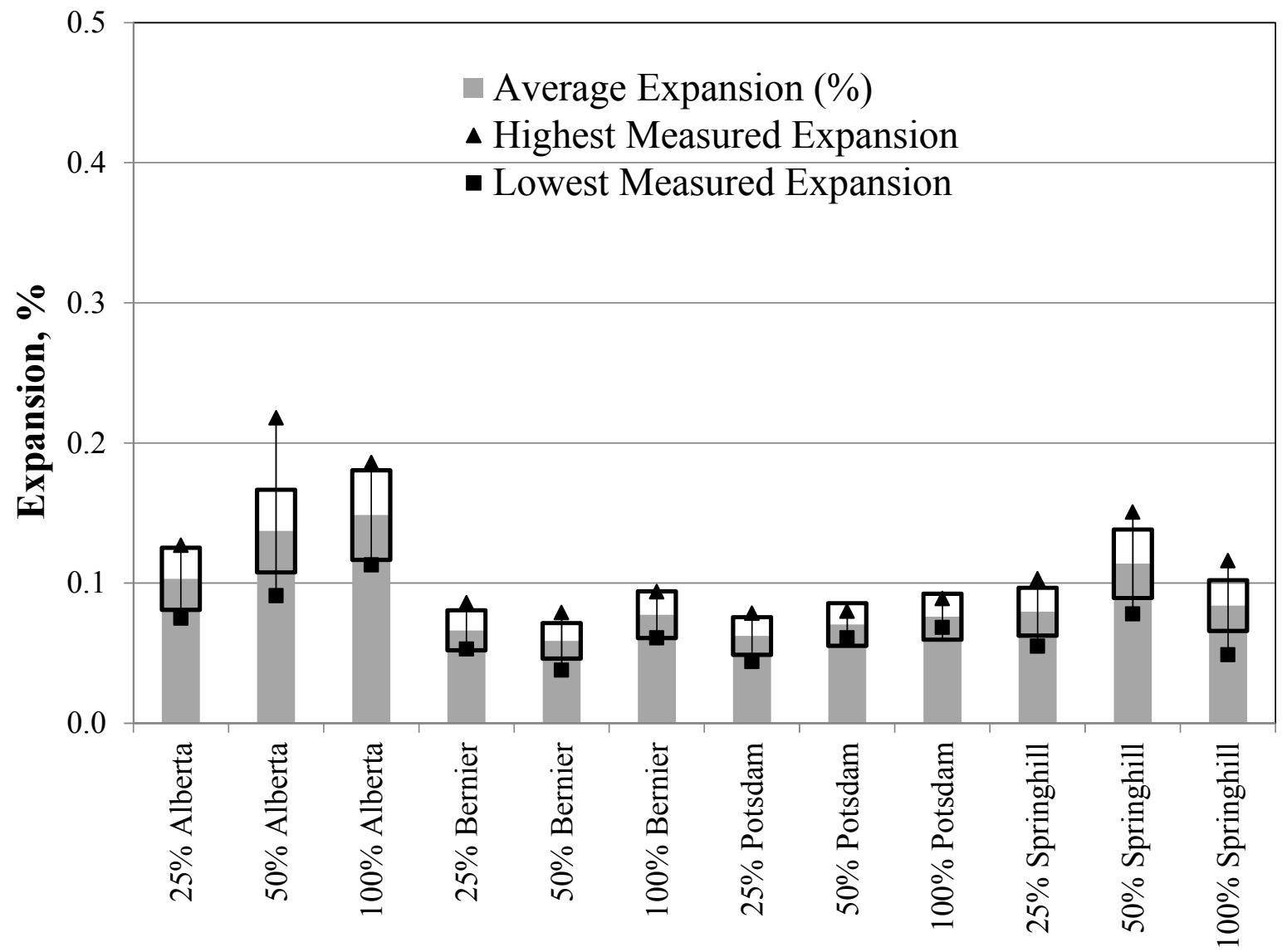

Figure 3-9: ASTM C1260 Precision Limits vs. Inter-Laboratory Study Data for Crusher's Fines RCA 


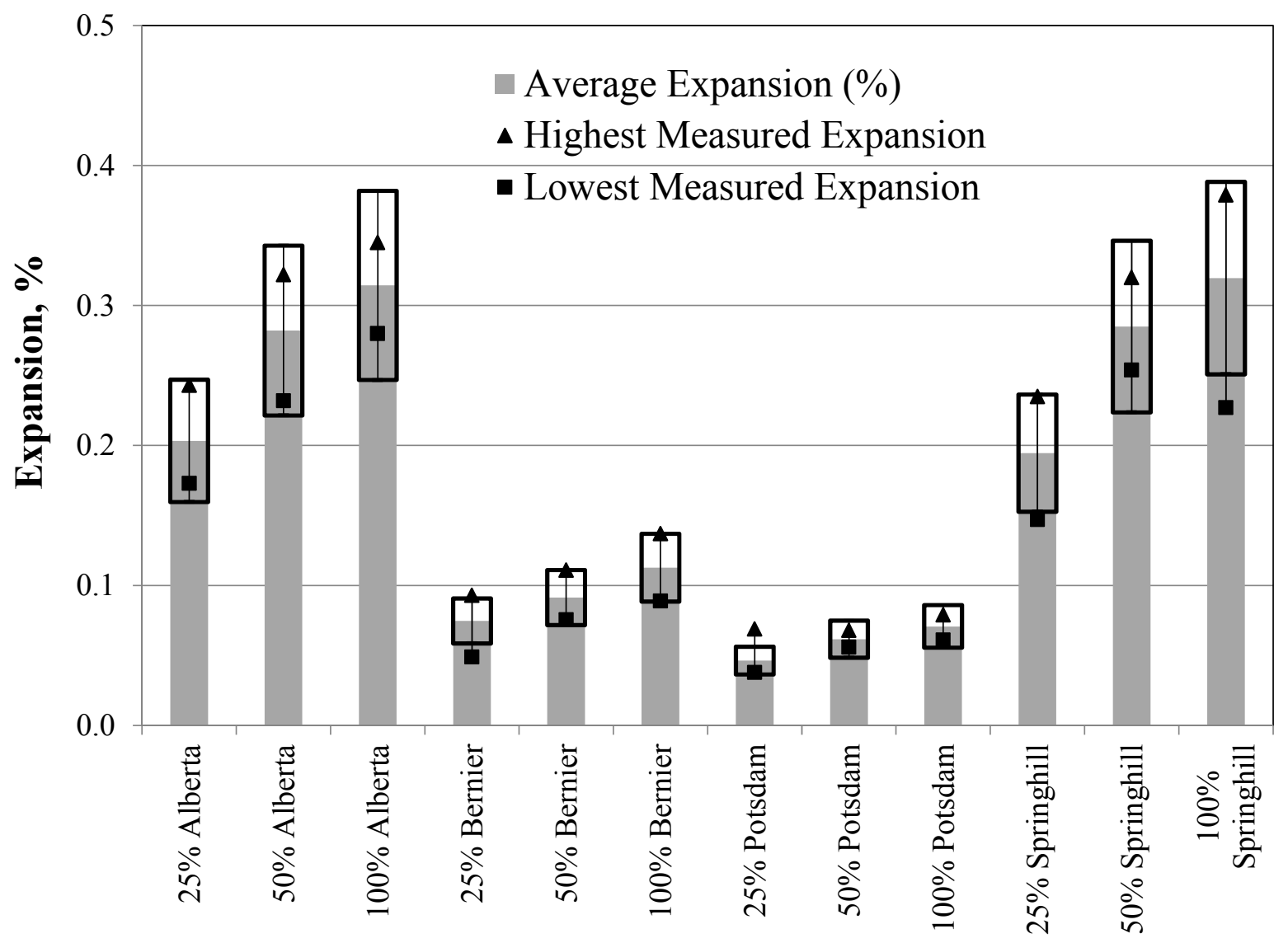

Figure 3-10: ASTM C1260 Precision Limits vs. Inter-Laboratory Study Data for Re-crushed RCA

The averages and COVs for expansion values at 14 days for each of the four universities are presented in Table 3.3 and Table 3.4. 
Table 3.3: ASTM Within-Laboratory Averages and COV for Each University for Re-crushed Coarse RCA

\begin{tabular}{|c|c|c|c|c|c|c|c|c|}
\hline University $\longrightarrow$ & \multicolumn{2}{|c|}{ UW } & \multicolumn{2}{|c|}{ RU } & \multicolumn{2}{|c|}{$\mathbf{L U}$} & \multicolumn{2}{|c|}{ OSU } \\
\hline Specimẹn Type & $\begin{array}{c}\text { AVG } \\
(\%) \\
\end{array}$ & $\begin{array}{c}\text { COV } \\
(\%) \\
\end{array}$ & $\begin{array}{c}\text { AVG } \\
(\%) \\
\end{array}$ & $\begin{array}{l}\text { COV } \\
(\%)\end{array}$ & $\begin{array}{c}\text { AVG } \\
(\%)\end{array}$ & $\begin{array}{c}\text { COV } \\
(\%) \\
\end{array}$ & $\begin{array}{c}\text { AVG } \\
(\%)\end{array}$ & $\begin{array}{l}\text { COV } \\
(\%)\end{array}$ \\
\hline $25 \%$ Alberta 1 & 0.173 & 0.58 & 0.231 & 2.60 & 0.209 & 4.13 & 0.199 & 3.24 \\
\hline $25 \%$ Alberta 2 & 0.177 & 1.13 & 0.236 & 2.60 & 0.213 & 1.74 & 0.188 & 4.29 \\
\hline $50 \%$ Alberta 1 & 0.233 & 0.25 & 0.316 & 1.90 & 0.279 & 1.65 & 0.299 & 2.86 \\
\hline $50 \%$ Alberta 2 & 0.233 & 0.89 & 0.308 & 1.20 & 0.302 & 4.77 & 0.288 & 2.17 \\
\hline $100 \%$ Alberta & 0.310 & 0.98 & 0.338 & 1.90 & 0.294 & 6.49 & 0.315 & 4.78 \\
\hline $25 \%$ Bernier & 0.051 & 6.26 & 0.074 & 5.30 & 0.087 & 4.14 & 0.087 & 4.57 \\
\hline $50 \%$ Bernier 1 & 0.093 & 0.76 & 0.083 & 7.40 & 0.095 & 3.20 & 0.102 & 11.45 \\
\hline $50 \%$ Bernier 2 & 0.090 & 2.32 & 0.081 & 7.80 & 0.098 & 1.02 & NA & NA \\
\hline 100\% Bernier & 0.103 & 2.57 & 0.132 & 3.70 & 0.090 & 1.92 & 0.126 & 2.86 \\
\hline $25 \%$ Potsdam & 0.040 & 5.16 & 0.065 & 4.80 & 0.038 & 77.7 & 0.042 & 4.12 \\
\hline $50 \%$ Potsdam & 0.059 & 0.97 & 0.066 & 3.00 & 0.064 & 2.37 & 0.057 & 1.02 \\
\hline 100\% Potsdam & 0.071 & 1.41 & 0.073 & 1.60 & 0.078 & 1.28 & 0.061 & 4.15 \\
\hline $25 \%$ Springhill & 0.148 & 1.56 & 0.220 & 6.10 & 0.201 & 3.67 & 0.209 & 2.76 \\
\hline 50\% Springhill & 0.255 & 0.39 & 0.300 & 3.30 & 0.281 & 1.44 & 0.305 & 5.19 \\
\hline $100 \%$ Springhill1 & 0.227 & 2.14 & 0.357 & 0.40 & 0.297 & 3.06 & 0.291 & 4.61 \\
\hline $100 \%$ Springhill2 & 0.256 & 0.44 & 0.373 & 1.30 & 0.316 & 3.07 & NA & NA \\
\hline 100\%Springhill3 & 0.247 & 1.10 & 0.415 & 2.00 & 0.390 & 2.91 & NA & NA \\
\hline
\end{tabular}

Table 3.4: ASTM Within-Laboratory Averages and COV for Each University for Crusher's Fines

\begin{tabular}{l|c|c|c|c|c|c|c|c}
\hline University $\longrightarrow$ & \multicolumn{2}{|c|}{ UW } & \multicolumn{2}{c|}{ RU } & \multicolumn{2}{c|}{ LU } & \multicolumn{2}{c}{ OSU } \\
\hline Specimen Type & $\begin{array}{c}\text { AVG } \\
(\%)\end{array}$ & $\begin{array}{c}\text { COV } \\
(\%)\end{array}$ & $\begin{array}{c}\text { AVG } \\
(\%)\end{array}$ & $\begin{array}{c}\text { COV } \\
(\%)\end{array}$ & $\begin{array}{c}\text { AVG } \\
(\%)\end{array}$ & $\begin{array}{c}\text { COV } \\
(\%)\end{array}$ & $\begin{array}{c}\text { AVG } \\
(\%)\end{array}$ & $\begin{array}{c}\text { COV } \\
(\%)\end{array}$ \\
\hline 25\% Alberta 1 & 0.086 & 0.67 & 0.108 & 3.60 & 0.116 & 5.24 & 0.128 & 24.2 \\
\hline 25\% Alberta 2 & 0.080 & 5.23 & 0.121 & 5.10 & 0.124 & 1.39 & 0.122 & 4.48 \\
\hline $50 \%$ Alberta 1 & 0.112 & 3.62 & 0.149 & 2.00 & 0.170 & 7.66 & 0.110 & 0.58 \\
\hline $50 \%$ Alberta 2 & 0.094 & 2.81 & 0.131 & 1.20 & 0.210 & 3.81 & 0.075 & 1.57 \\
\hline 100\% Alberta & 0.117 & 4.72 & 0.166 & 4.90 & 0.184 & 1.13 & 0.128 & 2.07 \\
\hline 25\% Bernier & 0.053 & 1.08 & 0.084 & 2.90 & 0.069 & 2.22 & 0.062 & 0.97 \\
\hline $50 \%$ Bernier 1 & 0.059 & 1.19 & 0.040 & 4.50 & 0.078 & 1.81 & 0.064 & 1.81 \\
\hline $50 \%$ Bernier 2 & 0.055 & 1.04 & 0.045 & 5.00 & 0.062 & 2.44 & 0.068 & 3.89 \\
\hline 100\% Bernier & 0.074 & 3.39 & 0.094 & 0.90 & 0.080 & 4.30 & 0.059 & 3.70 \\
\hline 25\% Potsdam & 0.045 & 3.37 & 0.079 & 1.70 & 0.058 & 2.00 & 0.068 & 4.51 \\
\hline $50 \%$ Potsdam & NA & NA & 0.080 & 2.50 & 0.062 & 1.87 & 0.070 & 8.41 \\
\hline 100\% Potsdam & 0.076 & 3.48 & 0.073 & 2.76 & 0.087 & 1.75 & 0.068 & 0.84 \\
\hline 25\% Springhill & 0.076 & 6.65 & 0.099 & 5.70 & 0.086 & 3.57 & 0.057 & 3.63 \\
\hline $50 \%$ Springhill & 0.078 & 0.90 & 0.124 & 5.30 & 0.151 & 6.81 & 0.103 & 26.51 \\
\hline 100\%Springhill1 & 0.093 & 3.23 & 0.052 & 5.50 & 0.086 & 4.72 & 0.067 & 6.88 \\
\hline 100\%Springhill2 & NA & NA & 0.107 & 3.20 & 0.115 & 1.33 & 0.069 & 9.04 \\
\hline
\end{tabular}


Between one-third and one half of the COVs exceed the limit of $2.94 \%$ for within-laboratory variation as defined by ASTM C 1260. The authors believe that the variation limits may need be relaxed to better fit the available data. Alternatively, the number of specimens could be increased from three to six to account for the increased variation seen in this research. However, to verify this further testing is recommended; some of which are presented in the results of Phase II.

\subsection{PHASE 2: UNIVERSITY OF WYOMING STUDY - PRELIMINARY RESULTS}

This section outlines preliminary investigations into long-term testing where two RCA and two natural aggregate sources were cast into exposure blocks. This represents initial findings and further results will be presented in Phase II. The objective of this testing is to catalyze ASR expansion by casting two highly reactive aggregates together in the same mixture. RCA that exhibited ASR in field conditions with highly reactive virgin aggregates was obtained from Wyoming pits. The two RCA samples came from the UW campus in Laramie. The first source was a set of outdoor concrete steps with severe ASR map cracking. This will be denoted as highly reactive (HR) RCA throughout this study. The second RCA sample, taken from the old UW power plant, was an indoor floor slab with moderate ASR deterioration. During this study this source will be designated as moderately reactive (MR). The on-campus physical plant crushed the HR and MR material to the aggregate sizes needed for the testing.

The two virgin aggregates used in the study were Knife River (KR) and Blackrock (BR). KR is a known reactive aggregate found in Cheyenne, and earlier ASTM C 1260 testing showed it exhibited high expansion rates and ultimate expansion values at 14 days of testing. In addition, BR exhibited high expansion rates in earlier ASTM C 1260 testing.

Specimen sets were cast for 100\% RCA, 50\% RCA and 25\% RCA mixtures with the remaining percentage filled by Knife River or Blackrock. A list of the specimens is as follows:

- $100 \%$ HR RCA;

- $100 \%$ MR RCA;

- $\quad 50 \%$ HR RCA/KR;

- $50 \%$ HR RCA/BR;

- $50 \% \mathrm{MR} \mathrm{RCA} / \mathrm{KR}$;

- $50 \%$ MR RCA/BR;

- $25 \% \mathrm{HR}$ RCA/KR;

- $25 \%$ HR RCA/BR;

- $25 \% \mathrm{MR}$ RCA/KR; and

- $25 \% \mathrm{MR} \mathrm{RCA} / \mathrm{BR}$.

Table 3.5 shows the required aggregate weights by sieve size for each mixture combination. In addition, the authors wanted to observe the effect of the cement alkalinity on this testing, so two different cement types were used: Holcim and Dakota. Holcim and Dakota cement have a total alkali content of approximately $0.7 \%$ and $0.2 \%$, respectively. 
Table 3.5: Material Requirements for Each RCA and Aggregate Type Mixture

\begin{tabular}{l|c|c|c|c|c}
\hline Sieve Size & $\begin{array}{c}100 \% \\
\text { RCA }(\mathrm{g})\end{array}$ & $50 \%$ RCA $(\mathrm{g})$ & $\begin{array}{c}50 \% \text { BR or } \\
\text { KR }(\mathrm{g})\end{array}$ & $25 \%$ RCA $(\mathrm{g})$ & $\begin{array}{c}75 \% \mathrm{BR} \text { or } \\
\text { KR }(\mathrm{g})\end{array}$ \\
\hline No. 8 & 99 & 49.5 & 49.5 & 24.7 & 74.3 \\
\hline No. 16 & 247.5 & 123.8 & 123.8 & 61.9 & 185.6 \\
\hline No. 30 & 247.5 & 123.8 & 123.8 & 61.9 & 185.6 \\
\hline No. 50 & 247.5 & 123.8 & 123.8 & 61.9 & 185.6 \\
\hline No. 100 & 148.5 & 74.2 & 74.2 & 37.1 & 185.6 \\
\hline Total $(\mathrm{g})$ & 990 & 495.1 & 495.1 & 247.5 & 742.5 \\
\hline
\end{tabular}

\subsubsection{Results}

Figure 3-11 displays the average 14-day expansions for each mixture type using the low alkalinity Dakota Cement. For the HR RCA, the 25\% HR-Blackrock specimens exhibited the highest average expansion while the $100 \%$ HR specimens exhibited the lowest average expansion. For the MR RCA, the $25 \%$ MR-BR specimens exhibited the highest average expansion while the $100 \%$ MR specimen exhibited the lowest average expansion. Overall, the specimen mixtures containing Blackrock aggregate exhibited higher expansion than the specimen mixtures containing Knife River aggregate. The 100\% MR and 100\% HR specimens displayed the lowest overall expansions for specimens using Dakota Cement.

For the HR RCA, the 25\% HR-Blackrock specimen exhibited the highest average expansion while the $100 \%$ HR specimen exhibited the lowest average expansion. For the MR RCA, the $25 \%$ MR-BR specimen exhibited the highest average expansion while the $100 \%$ MR specimen exhibited the lowest average expansion. Overall, the specimen mixtures containing Blackrock aggregate exhibited higher expansion than the specimen mixtures containing Knife River aggregate. The 100\% MR and 100\% HR specimens displayed the lowest overall expansions for specimens using Holcim Cement.

For the $25 \%$ and $50 \%$ Blackrock mixture ratios, the $25 \%$ mixtures exhibited higher average expansions than the $50 \%$ mixtures. 


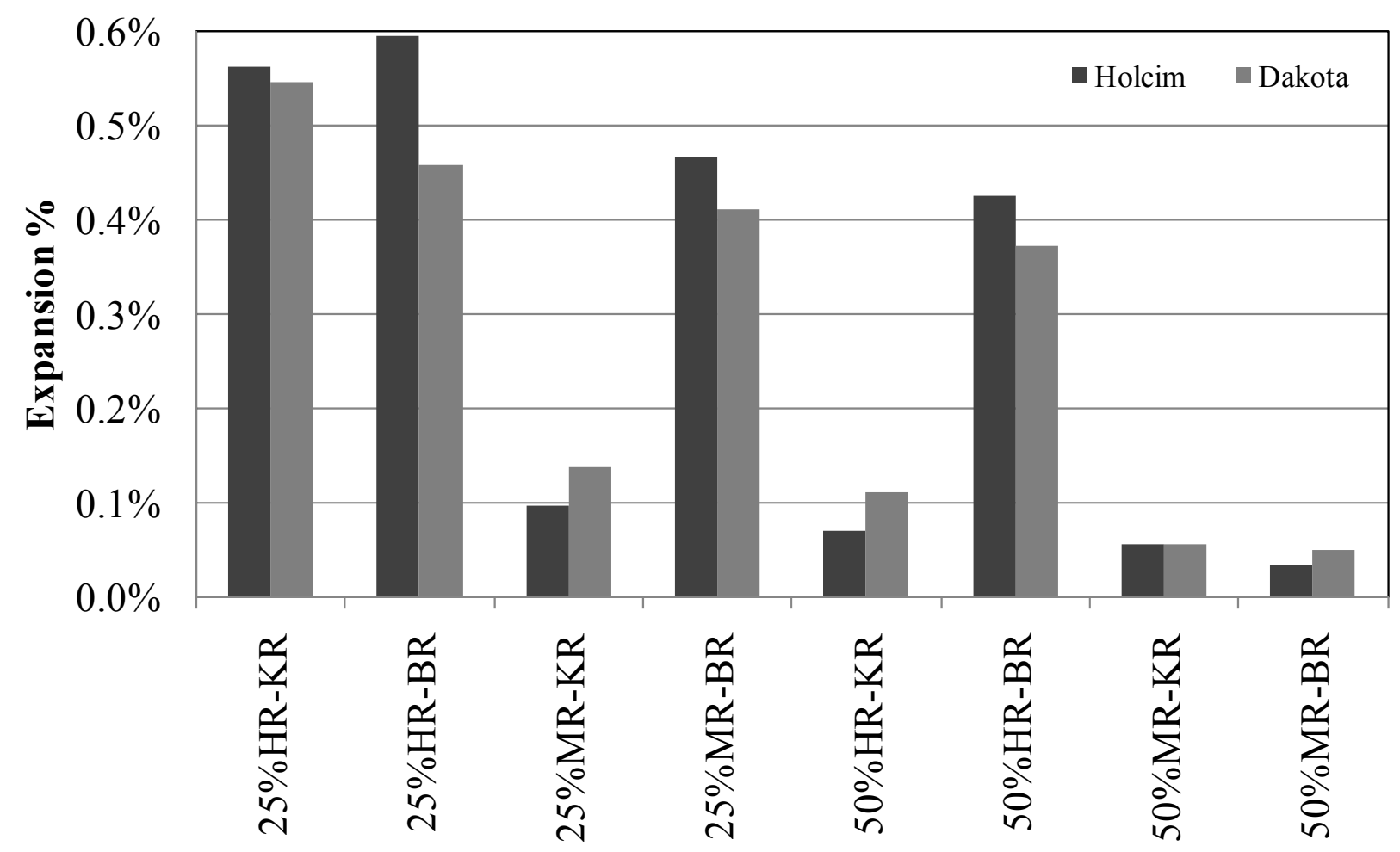

Figure 3-11: Average 14-day expansion results for each mixture proportion

Figure 3-11 displays the average 14-day results for each of the mixture proportions as well as both of the cement types. For the $25 \%$ HR-BR, $25 \%$ MR-BR, 50\% HR-BR and $50 \%$ MR-BR mixtures, the high alkalinity cement (Holcim) specimens exhibited a higher 14-day expansion that the low alkalinity (Dakota) specimen. For the 50\% HR-KR, 50\% MR-KR and 100\% HR mixtures, the Dakota specimens exhibited higher 14-day expansions than the Holcim specimens. For the $100 \%$ MR mixture, both the Holcim specimen and the Dakota specimen displayed the same exact expansion.

Table 3.6 displays the averages and the allowable ASTM precision for within-laboratory results. ASTM C 1260 gives recommendations of precision for within-laboratory results. For "Within Laboratory Precision - It has been found that the average multi-laboratory coefficient of variation for materials with an average expansion greater than $0.1 \%$ at 14 days is $2.94 \%$. Therefore the results of two properly conducted tests within the same laboratory on specimens of a sample of aggregate should not differ by more than 8.3\%." (ASTM, 2010). This precision was used to determine an acceptable range for each of the proportion mixtures.

So far in this phase of testing, 10 out of the 20 mixtures exhibited expansions that conformed to the $2.94 \%$ coefficient of variation limit for within laboratory precision defined by ASTM. The conforming mixtures include: 100\% HR (Holcim), 50\% HR-KR (Dakota), 50\% HR-BR (Holcim), 50\% HR-BR (Dakota), 50\% MR-KR (Dakota), 50\% MR-BR (Holcim), 25\% HR-BR (Holcim), 25\% MR-BR (Holcim) and 25\% MR-BR (Dakota). On the other hand, all of the mixtures fell within the $8.3 \%$ limit on average measurements. 
The hypothesis of this research phase was that using recycled aggregates in new concrete mixtures could become an important mitigation technique. More formal conclusions will be provided when the test data is complete.

Table 3.6: Fourteen-Day Averages and ASTM Precision for Each RCA and Aggregate Type

\begin{tabular}{|c|c|c|c|c|c|c|}
\hline Specimen Type & $\begin{array}{c}\text { Number } \\
\text { of } \\
\text { Samples }\end{array}$ & $\begin{array}{c}\text { Average } \\
\text { Expansion } \\
(\%)\end{array}$ & $\begin{array}{c}\text { Coefficient } \\
\text { of } \\
\text { Variation } \\
(\%) \\
\end{array}$ & $\begin{array}{c}\text { ASTM } \\
\text { Low } \\
\text { Expansion } \\
(\%) \\
\end{array}$ & $\begin{array}{c}\text { ASTM } \\
\text { High } \\
\text { Expansion } \\
(\%) \\
\end{array}$ & $\begin{array}{c}\text { Number } \\
\text { of } \\
\text { Outliers }\end{array}$ \\
\hline $100 \% \mathrm{HR}(\mathrm{H})$ & 3 & .034 & 1.71 & .031 & .036 & 0 \\
\hline $100 \% \mathrm{HR}(\mathrm{D})$ & 3 & .049 & 5.10 & .045 & .053 & 0 \\
\hline $100 \% \mathrm{MR}(\mathrm{H})$ & 3 & .056 & 5.49 & .051 & .060 & 0 \\
\hline 100\%MR (D) & 3 & .056 & 4.52 & .051 & .060 & 0 \\
\hline $50 \% \mathrm{HR} / \mathrm{KR}(\mathrm{H})$ & 3 & .097 & 3.63 & .089 & .105 & 0 \\
\hline $50 \% \mathrm{HR} / \mathrm{KR}(\mathrm{D})$ & 3 & .137 & 1.68 & .126 & .149 & 0 \\
\hline $50 \% \mathrm{HR} / \mathrm{BR}(\mathrm{H})$ & 3 & .465 & 2.07 & .426 & .504 & 0 \\
\hline $50 \% \mathrm{HR} / \mathrm{BR}(\mathrm{D})$ & 3 & .412 & 2.30 & .377 & .446 & 0 \\
\hline $50 \% \mathrm{MR} / \mathrm{KR}(\mathrm{D})$ & 3 & .111 & 1.80 & .102 & .120 & 0 \\
\hline $50 \% \mathrm{MR} / \mathrm{BR}(\mathrm{H})$ & 3 & .426 & 1.54 & .391 & .461 & 0 \\
\hline $50 \% \mathrm{MR} / \mathrm{BR}(\mathrm{D})$ & 3 & .377 & 3.69 & .345 & .408 & 0 \\
\hline $25 \% \mathrm{HR} / \mathrm{KR}(\mathrm{D})$ & 3 & .158 & 2.04 & .145 & .171 & 0 \\
\hline $25 \% \mathrm{HR} / \mathrm{BR}(\mathrm{H})$ & 3 & .562 & 1.43 & .516 & .609 & 0 \\
\hline $25 \% \mathrm{HR} / \mathrm{BR}(\mathrm{D})$ & 3 & .546 & 3.70 & .500 & .591 & 0 \\
\hline $25 \% \mathrm{MR} / \mathrm{KR}$ (D) & 3 & .153 & 3.64 & .140 & .166 & 0 \\
\hline $25 \% \mathrm{MR} / \mathrm{BR}(\mathrm{H})$ & 3 & .595 & 1.99 & .545 & .644 & 0 \\
\hline $25 \% \mathrm{MR} / \mathrm{BR}(\mathrm{D})$ & 3 & .458 & 2.43 & .420 & .496 & 0 \\
\hline
\end{tabular}




\subsection{DEPARTMENT OF TRANSPORTATION SURVEY}

The research team identified the need for a data management system to record and track demolished concrete pavements/structures/buildings that may have the potential for future reclamation/recycling as RCA in new concrete and other civil engineering projects. An information request/user poll will be sent out to key personnel from a variety of public and private agencies (e.g., state DOTs, FHWA, NRMCA, PCA, AASHTO, ACPA, etc.) to identify the specific types of information that would be most beneficial for inclusion in a database that would be used to track concrete demolition and deconstruction projects. This database is intended to serve as a template for state and federal adoption as a way to maintain records about specific projects where RCA may be reclaimed and/or recycled for future use. This is a key step in establishing the type of records that will enable the best decision-making processes for using RCA in new projects. In addition, it may also help to identify sources of RCA that may be truly undesirable for incorporation in new concrete, and these particular sources may subsequently diverted for use in lower risk applications such as fill, base, sub-base material or reclamation for re-processing into new cementitious components.

This was Task 2 in Phase I of the research project. The initiation of this task was delayed due to the significant increase in the ASTM C 1260 testing outlined in Section 3.0. The research team also had to go through review by the Internal Review Board (IRB) at OSU since the survey involves feedback from human participants. The survey has been approved by OSU's IRB and was sent out to participants in January 2011. Appendix 7.2 contains the sample survey that was sent out to various participating agencies. Full results will be provided in the Phase II report.

The outcome of Task 2 will be a template for a database that contains information specific to tracking demolished and reclaimed/stockpiled recycled concrete, which can be used by state DOTs, specifiers, designers, contractors and other interested agencies to track specific information about concrete which is demolished and may be reclaimed for use as aggregate.. This database can be utilized by a wide variety of agencies as a tool to aid in decision-making processes to best utilize recycled concrete aggregates. It is expected that small focus groups will aid in Web-based testing of the database to ensure ease of use and inclusion of expected features from initial polling. 


\subsection{SUMMARY AND CONCLUSIONS}

ASTM C 1260 testing provided a unique opportunity for a multi-laboratory study using RCA from blocks in a CANMET field site. Data from four universities shows that as the percent of RCA increases so does the expansion. This method successfully determined reactivity of RCA materials.

Although there was not a clear trend between crusher's fines and coarse aggregates, the crusher's fines results varied more due to the process of crushing the aggregate. Most of the inter-laboratory data met the $43 \%$ limit criteria specified by ASTM, and few data sets met the $15.2 \% \mathrm{COV}$ requirement for multi-laboratory variation. More data met the $2.9 \% \mathrm{COV}$ for within-laboratory precisions. These results suggest that the ASTM limits on precision and bias need to be relaxed. Alternatively, the number of specimens could be increased from three to six to account for the higher variability of RCA material. The authors recommend further testing of RCA at several laboratories to quantify an appropriate value for the standard deviation. The results confirm that different levels of crushing (crusher's fines versus re-crushed fines) can produce different reactivity results. This trend was not consistent across all RCA sources, however, which merits further study. The authors recommend petrographic analysis of the RCAs to determine the level of cracking and amount of adhered mortar in each level of RCA crushing to help identify why this is different across different RCA sources.

Overall, the following conclusions were made:

- Modifications to standard aggregate testing and characterization standards are necessary for RCA.

- Absorption capacity testing required at least a 24 -hour soaking period to take up $95 \%$ of the material's absorption capacity.

- Modifications to ASTM C 305 were required for properly mixing mortars containing RCA, including a soaking period of 30 minutes for all aggregate (including RCA) to ensure proper absorption by dry aggregate and adequate mixing.

- Based on testing in this research project precision and bias statements in ASTM C 1260 (for virgin aggregate) do not apply to RCA. Additional testing from at least six laboratories testing the same materials would be needed to properly establish precision and bias statements.

Recommendations for future research include:

- Establish baseline ASTM C 1293 data and outdoor exposure block testing to benchmark the long-term performance of concrete containing RCA that may have the potential for ASR.

- Characterize by microscopy reaction products, extent of damage (through Damage Rating Index system) and location of damage within the microstructure, which will aid in 
determining how ASR-related damage in concrete containing RCA compares to that in concrete with virgin ASR susceptible aggregates. Ultimately, this is needed to address mitigation and possible damage in existing concrete.

- Increase the amount of testing done on RCA between these four laboratories, and include at least two more laboratories so that modifications can be made to ASTM C 1260 testing to include RCA.

- Determine if standard mitigation options (e.g., supplementary cementing materials and/or chemical admixtures) are also viable options to control ASR in concrete containing RCA.

- Provide technical guidance for the industry and users of RCA (e.g., state DOTs, readymix concrete suppliers and contractors). 


\subsection{REFERENCES}

ASTM C 1260-08, Standard Test Method for Potential Alkali Reactivity of Aggregates (MortarBar Method), Annual Book of Standards, ASTM International, West Conshohocken, PA, V. 4.02, 2008, 5 pp.

Aydin, S., Baradan, B., \& Karatay, C. (2010). The effect of grinding process on mechanical properties and alkali-silica reaction resistance of fly ash incorporated cement mortars. Powder Technology, 68-72.

Berube, M. A., \& Fournier, B. (2007). Alkali Aggregate Reaction in Concrete: a review of basic concepts and engineering implications. Canadian Journal of Civial Engineering, 167-191.

Federal Highway Administration National Review, 2. (2003). Recycled Concrete Aggregate. Retrieved from http://www.fhwa.dot.gov/pavement/recycling/rca.cfm

Fathifazl, G., Razaqpur, A. G., Isgor, O. B., Abbas, A., Fournier, B., Foo, S. "Flexural Performance of Steel-Reinforced Recycled Concrete Beams". ACI Materials Journal, V.106, No. 6, November-December 2009. Pp.858-867

Fournier, B., \& Malhotra, V. M. (1999). Evaluation of Laboratory Test Methods for Alkali Silica Reactivity. Cement, Concrete, and Aggregates, 173-184.

Fournier, B., Ideker, J., Folliard, K., Thomas, M. D., Nkinamubanzi, P.-C., \& Chevrier, R. (2009). Effect of environmental conditions on expansion in concrete due to alkali-silica reaction. Materials Characterization, 669-679.

Fournier, B., Nkinamubanzi, P.-C., Lu, D., Thomas, M. D., Folliard, K., \& Ideker, J. (2006). Evaluating potential alkali-reactivity of concrete aggregates - How reliable are the current and new test methods? Ibero-Americano Sobre "Concreto Estrutural".

Hobbs, D. W., Alkali - Silica Reaction in Concrete, Thomas Telford, London, England 1988, 659 pp.

International, A. (2010). Standard Test Method for Potential Alkali Reactivity of Aggregates (Mortar Bar Method). Standard Test Method for Potential Alkali Reactivity of Aggregates (Mortar Bar Method) . West Conshohocken, PA, US: ASTM International.

Nagataki, S., Gokce, A., Saeki, T., Hisada, M. “Assessment of Recycling Process Induced Damage Sensitivity of Recycled Concrete Aggregates". Cement and Concrete Research, Vol. 24, Issue 6, 2004. Pp. 965-971. 
Scott IV, H., \& Gress, D. (2003). Mitigating Alkali Silica Reaction in Recycled Concrete. In Recycling Concrete and Other Materials for Sustainable Development (pp. 61-76). American Concrete Institute.

Shayan, A \& Xu, A. (2003) "Performance and Properties of Structural Concrete Made with Recycled Concrete Aggregate”. ACI Materials Journal, V 100, No 5, September/October 2003. Pp.371-380

Shehata, M. H., Christidis, C, Mikhaiel, W., Rogers, C., \& Lachemi, M. "Reactivity of Reclaimed Concrete Aggregate Produced from Concrete Affected by Alkali-Silica Reaction". Cement and Concrete Research, Volume 40, Is. 4, 2010. Pp. 575-582

Stark, D. (1996). The Use of Recycled-Concrete Aggregate from Concrete Exhibiting AlkaliSilica Reactivity. In Research and Development Bulletin RD114. Skokie, IL: Portland Cement Association.

Thomas, M. D., Fournier, B., Folliard, K. J., Ideker, J., \& Shehata, M. (2006). Test Methods for Evaluating Preventative Measures for Controlling Expansion due to Alkali-Silica Reaction in Concrete. Cement and Concrete Research , 1842-1856.

Thomas, M. D. A., Fournier, B., Folliard, K. J., Shehata, M., Ideker, J. H. and Rogers, C., "Performance Limits for Evaluating Supplementary Cementing Materials using the Accelerated Mortar Bar Test," ACI Materials Journal, V. 104, No. 2, March, 2007, pp. 115-122.

US Department of Transportation Strategic Plan, F. Y.-2. (n.d.). New Ideas for a Nation on the Move. Retrieved from http://www.dot.gov/about_dot.html

Xu, Z., Shen, Y., Lu, D., Deng, M., Lan, X., Hu R., Tang, M., 1998 "Investigation on A New Test Method for Determining the Alkali Silica Reactivity of Aggregates," Journal of Nanjing University of Chemical Technology, 20 [2] pp. 1-7.

Xu, Z., Lan, X., Deng, M. and Tang, M., "A New Accelerated Method for Determining the Potential Alkali-Carbonate Reactivity," Proceedings of the $11^{\text {th }}$ International Conference on Alkali-Aggregate Reactivity, Bérubé, M.A., Fournier, B. and Durand, B. eds., CRIB, Sainte-Foy Québec, Canada, June 2000, pp. 129-138. 


\subsection{APPENDICES}

\subsection{SUMMARY OF RESULTS}

A complete description of results used in the interlaboratory validation is presented in Figure 7-1

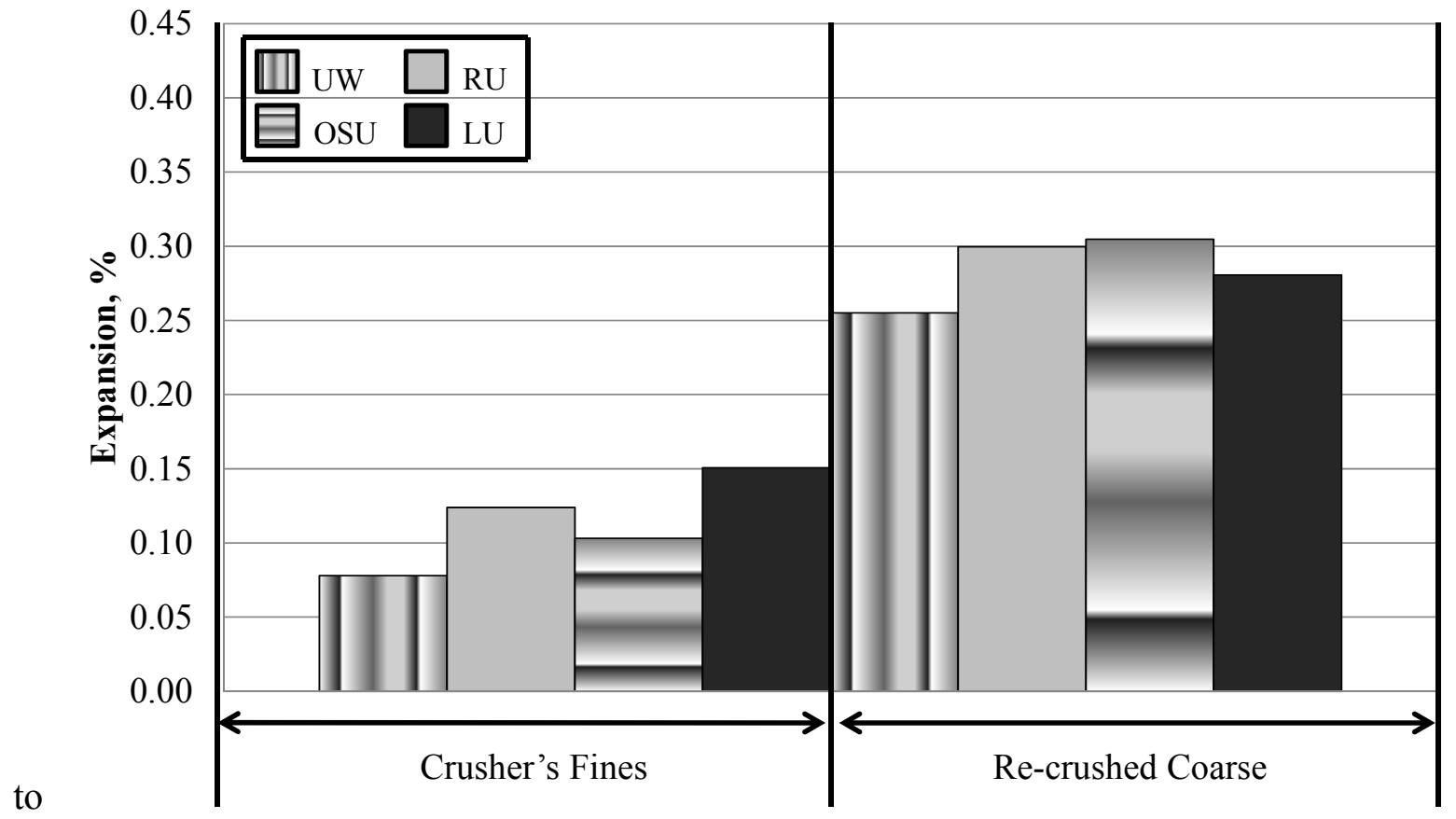

Figure 7-12. Data is broken down by source and percentage of replacement material. 


\subsubsection{Alberta RCA}

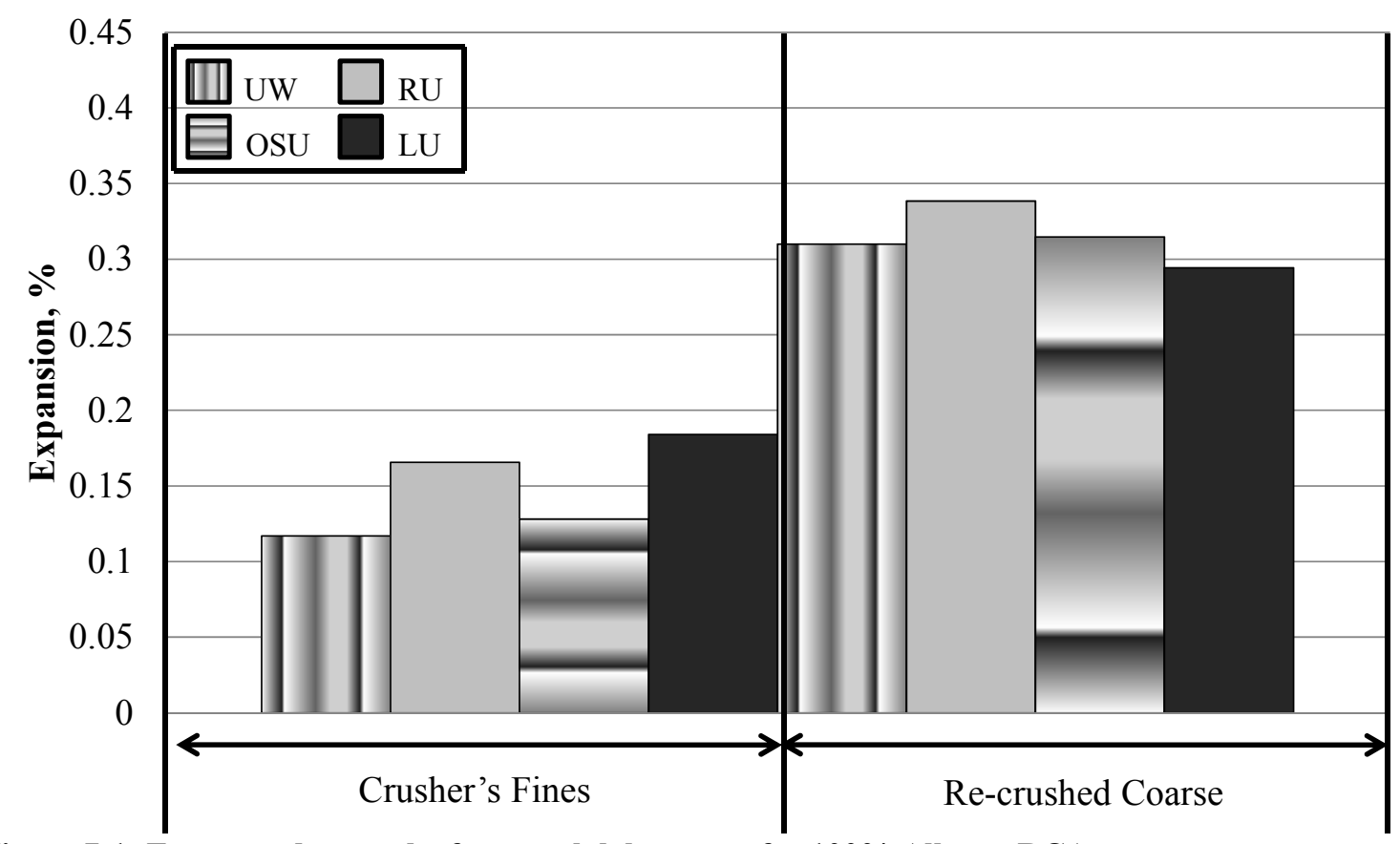

Figure 7-1: Fourteen-day results from each laboratory for 100\% Alberta RCA

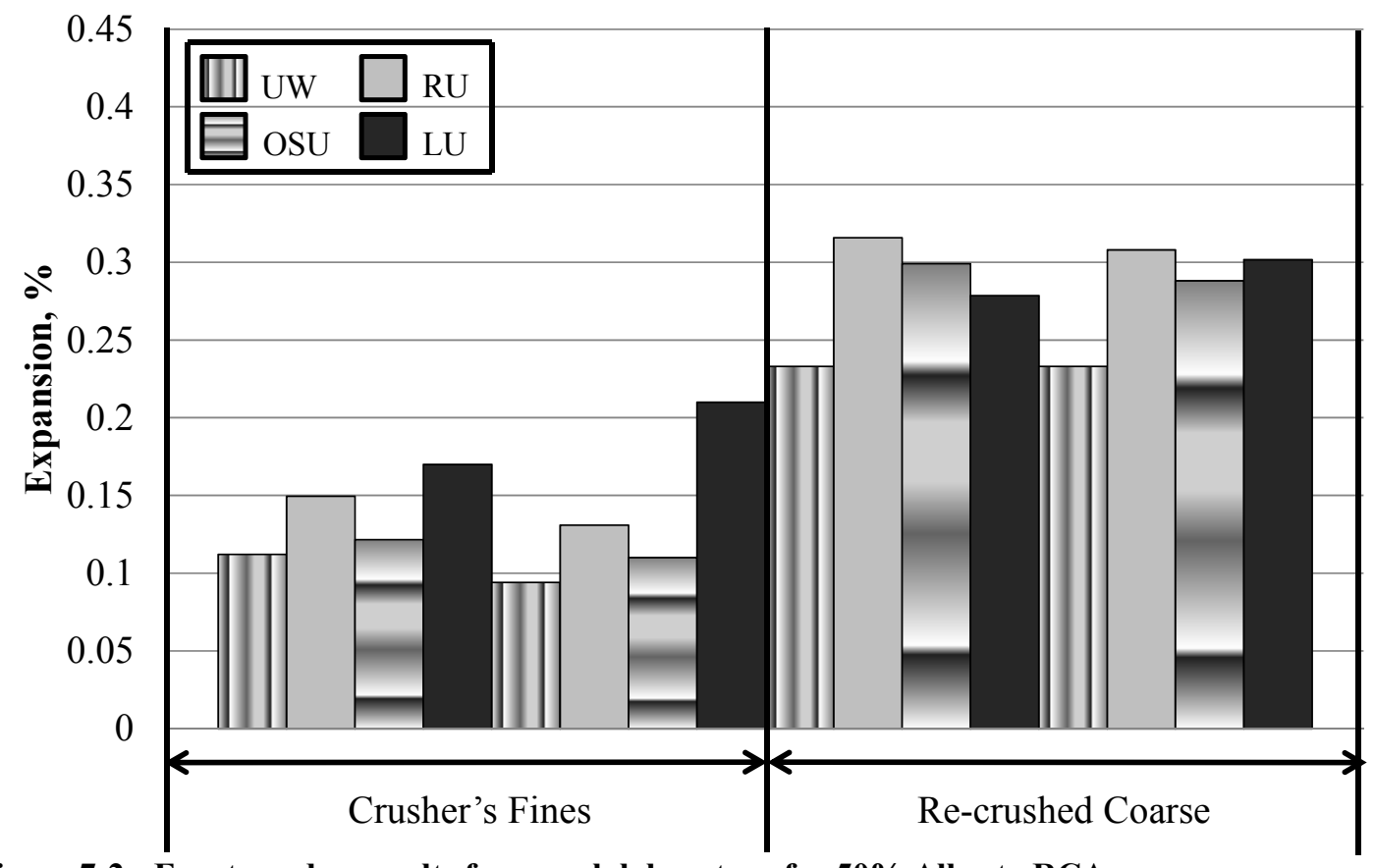

Figure 7-2: Fourteen-day results from each laboratory for $\mathbf{5 0 \%}$ Alberta RCA 


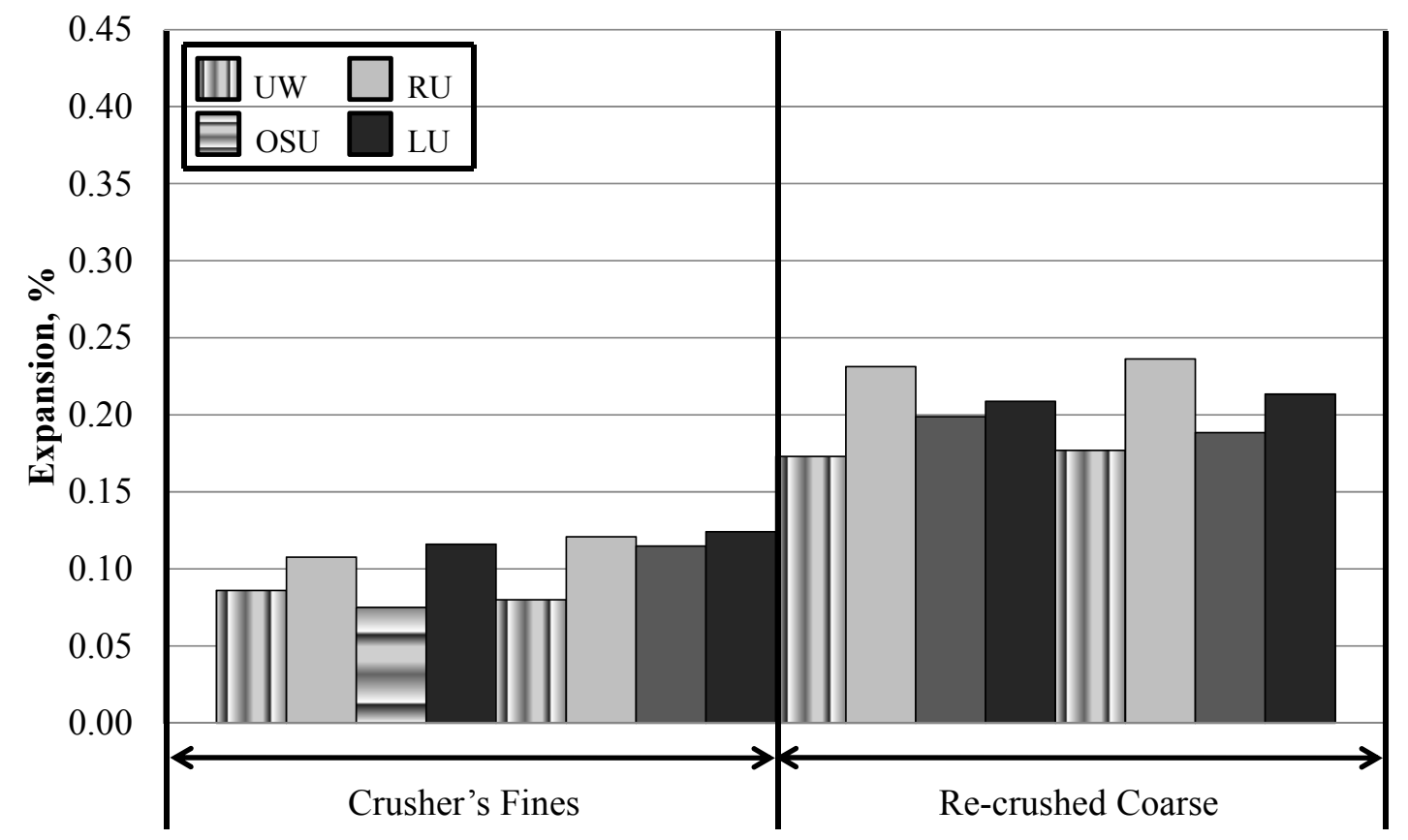

Figure 7-3: Fourteen-day results from each laboratory for 25\% Alberta RCA

\subsubsection{Bernier RCA}

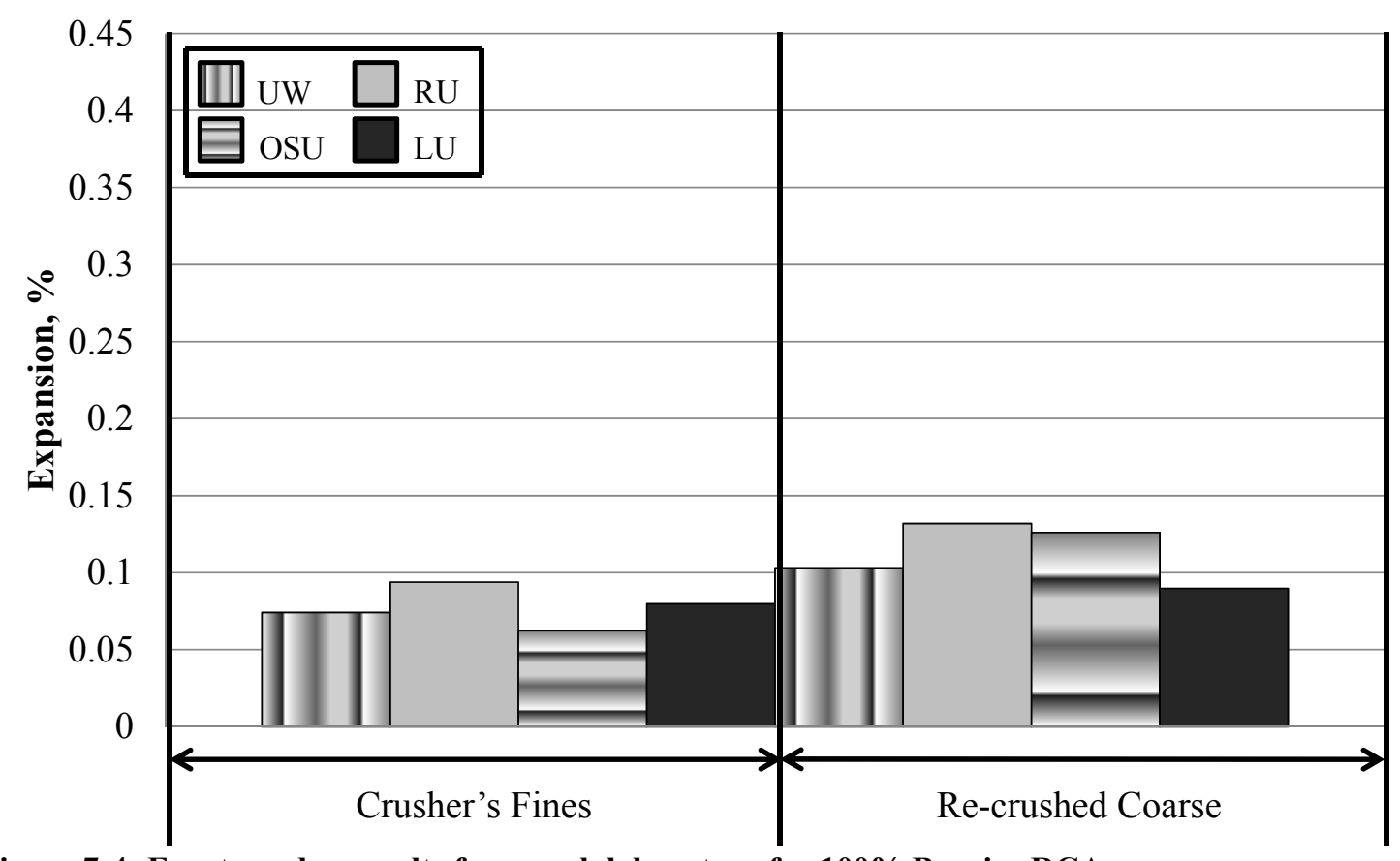

Figure 7-4: Fourteen-day results from each laboratory for $100 \%$ Bernier RCA 


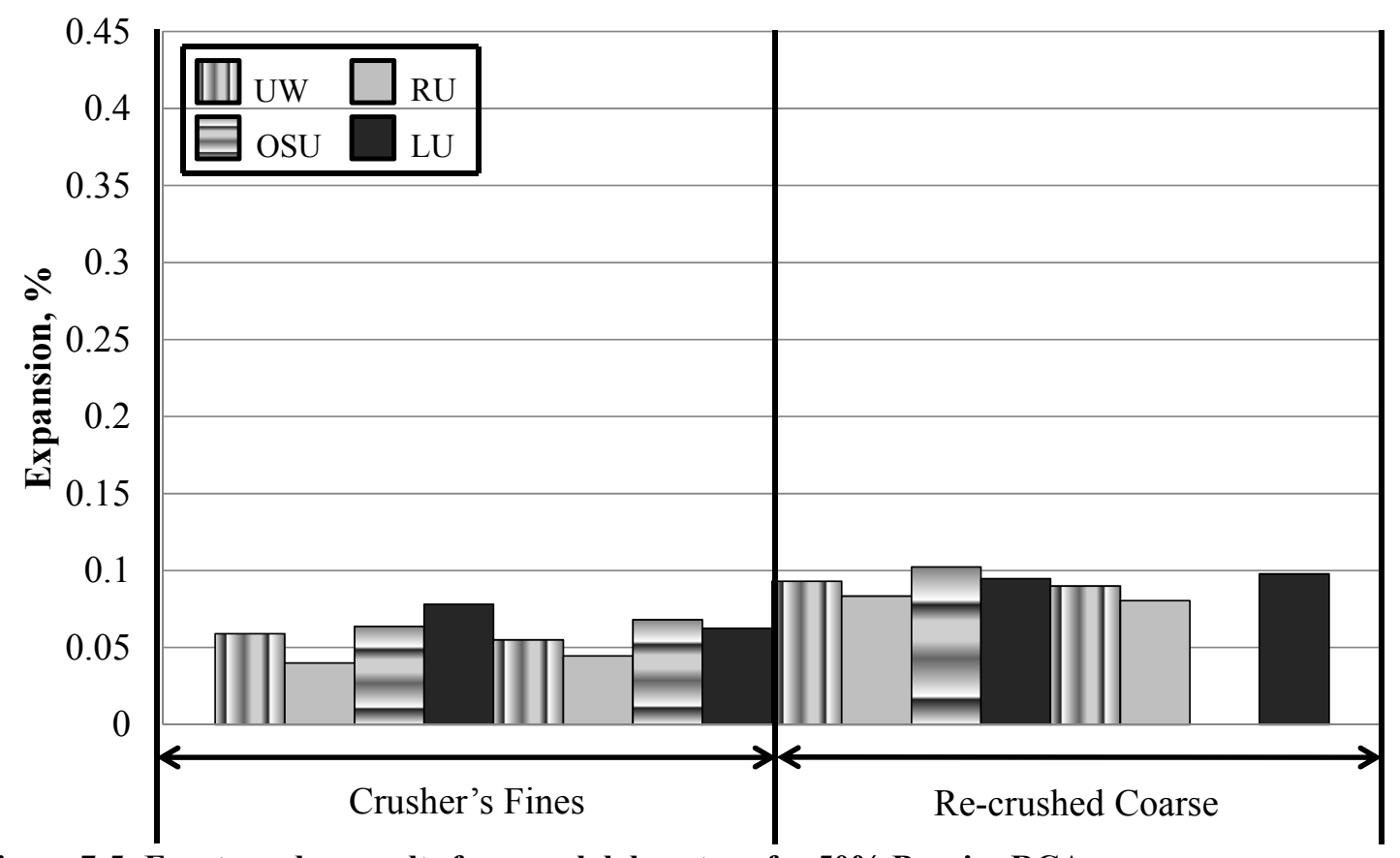

Figure 7-5: Fourteen-day results from each laboratory for 50\% Bernier RCA

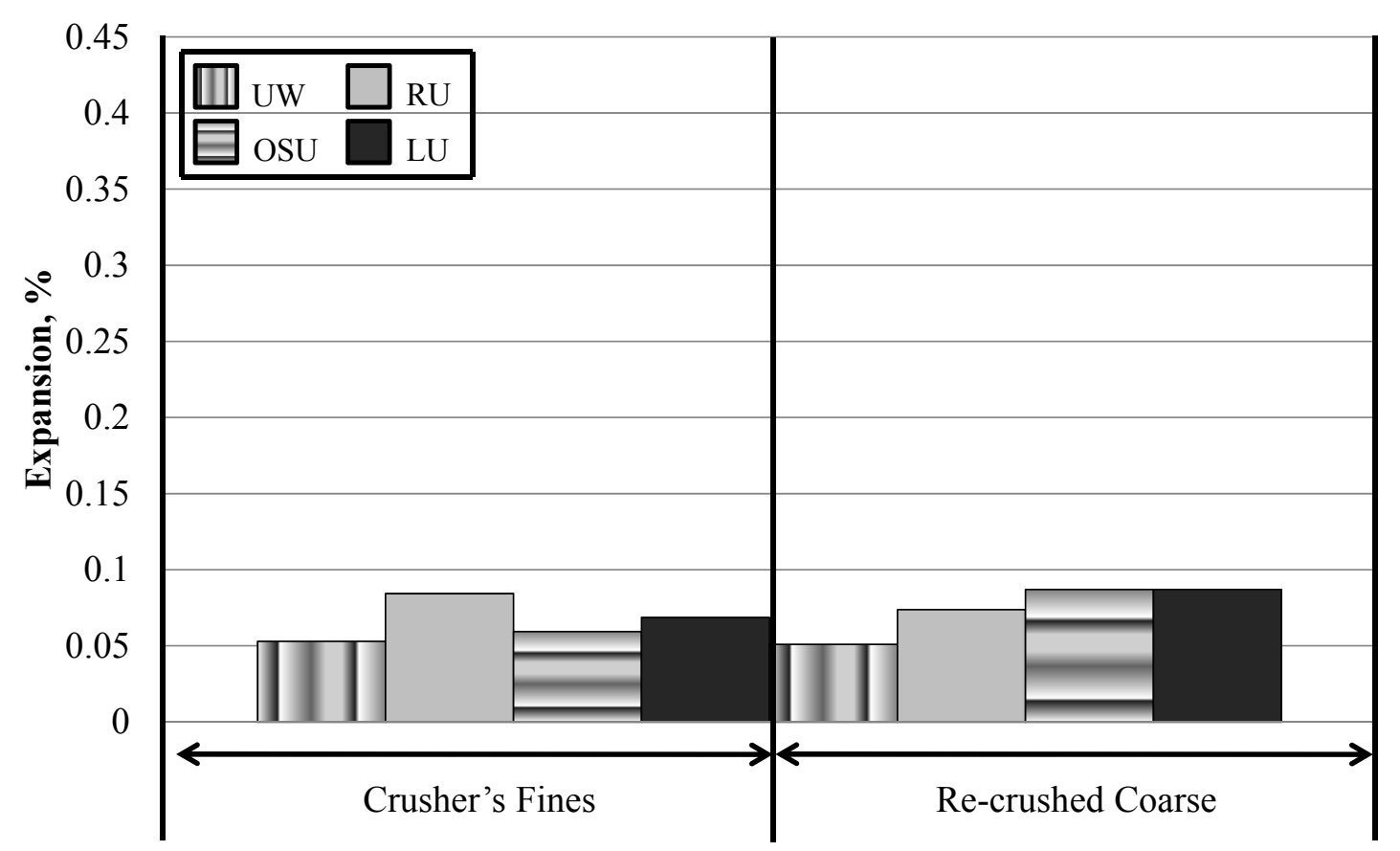

Figure 7-6: Fourteen-day results from each laboratory for $25 \%$ Bernier RCA 


\subsubsection{Potsdam RCA}

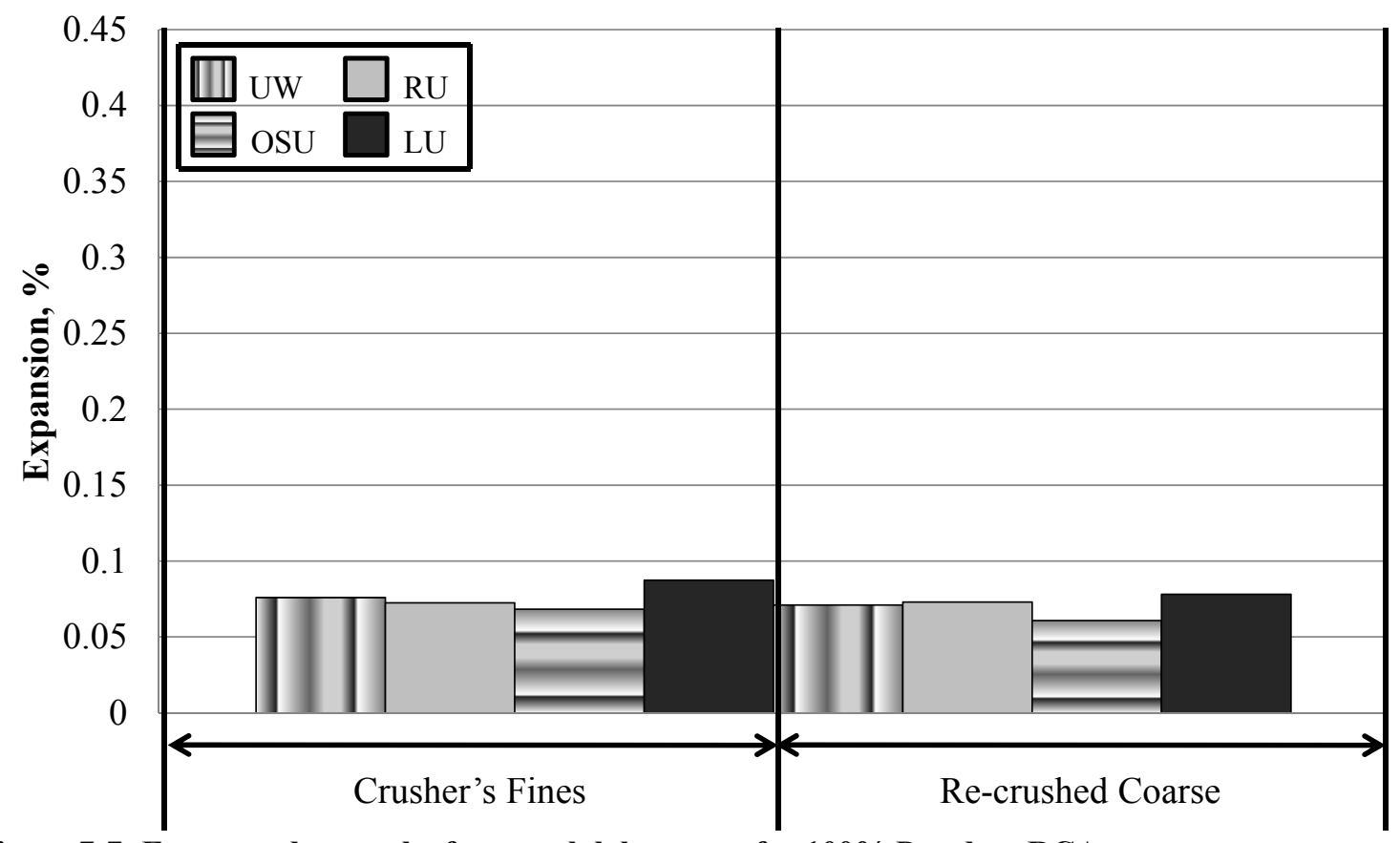

Figure 7-7: Fourteen-day results from each laboratory for $100 \%$ Potsdam RCA

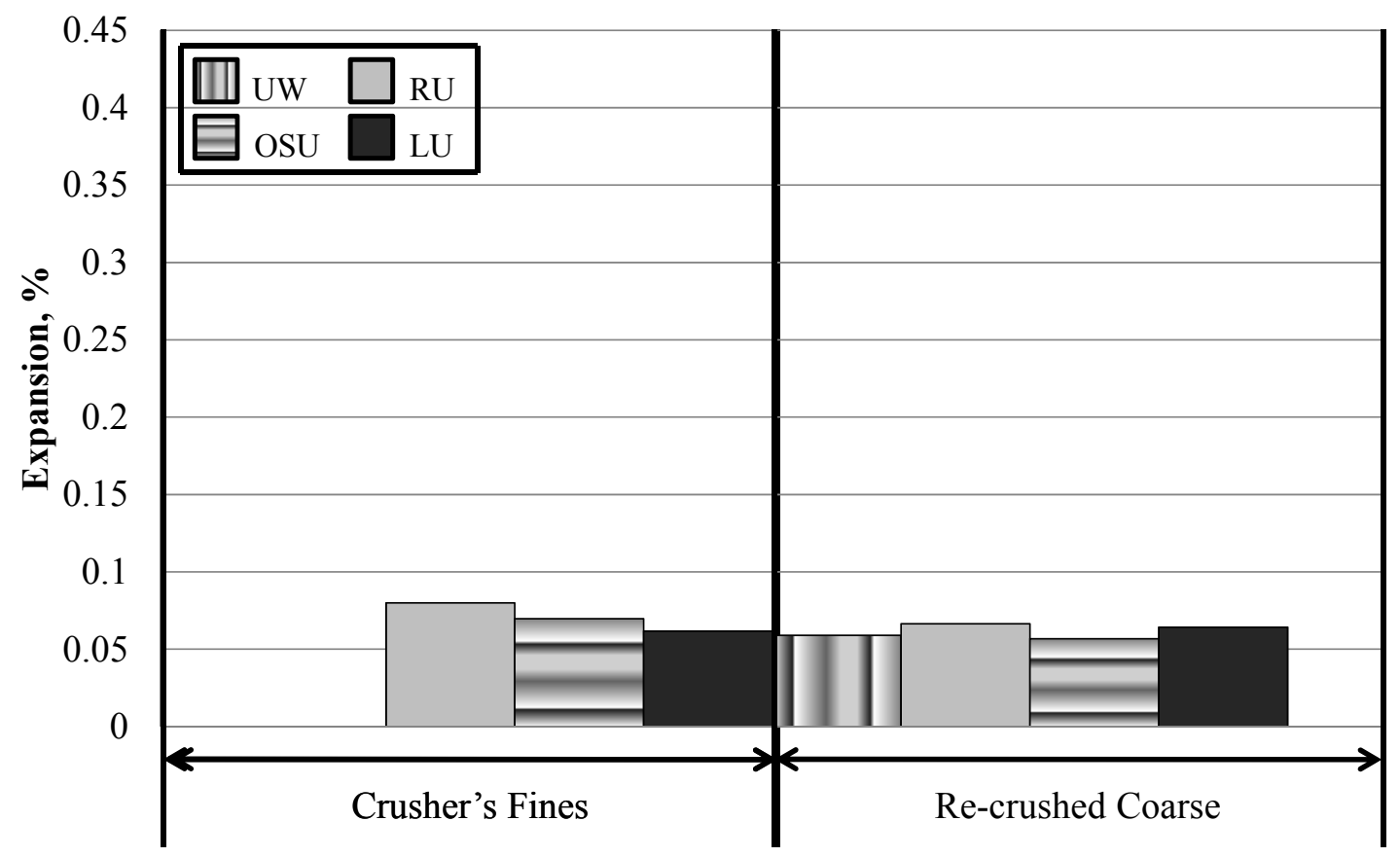

Figure 7-8: Fourteen-day results from each laboratory for 50\% Potsdam RCA 


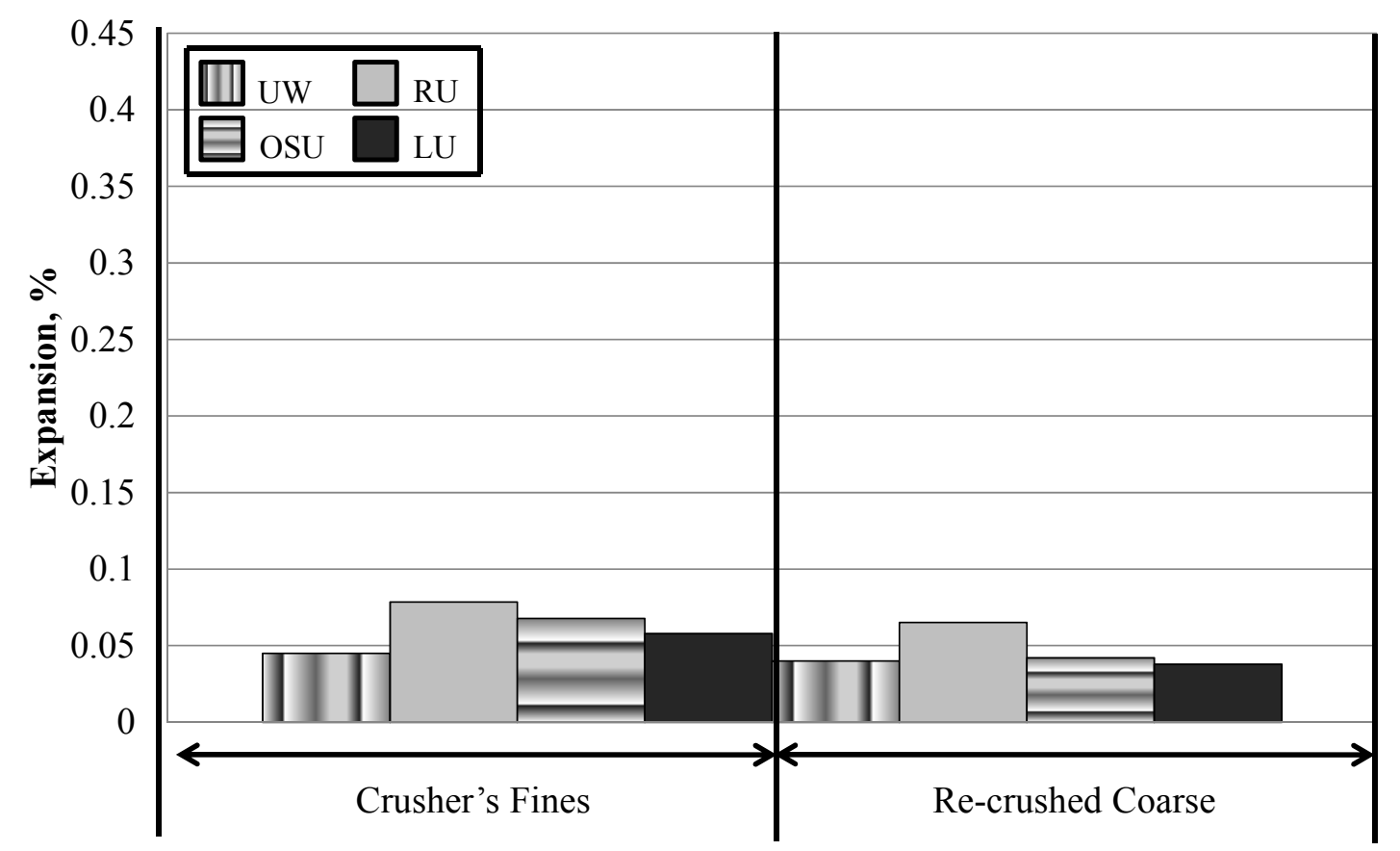

Figure 7-9: Fourteen-day results from each laboratory for $25 \%$ Potsdam RCA

\subsubsection{Springhill RCA}

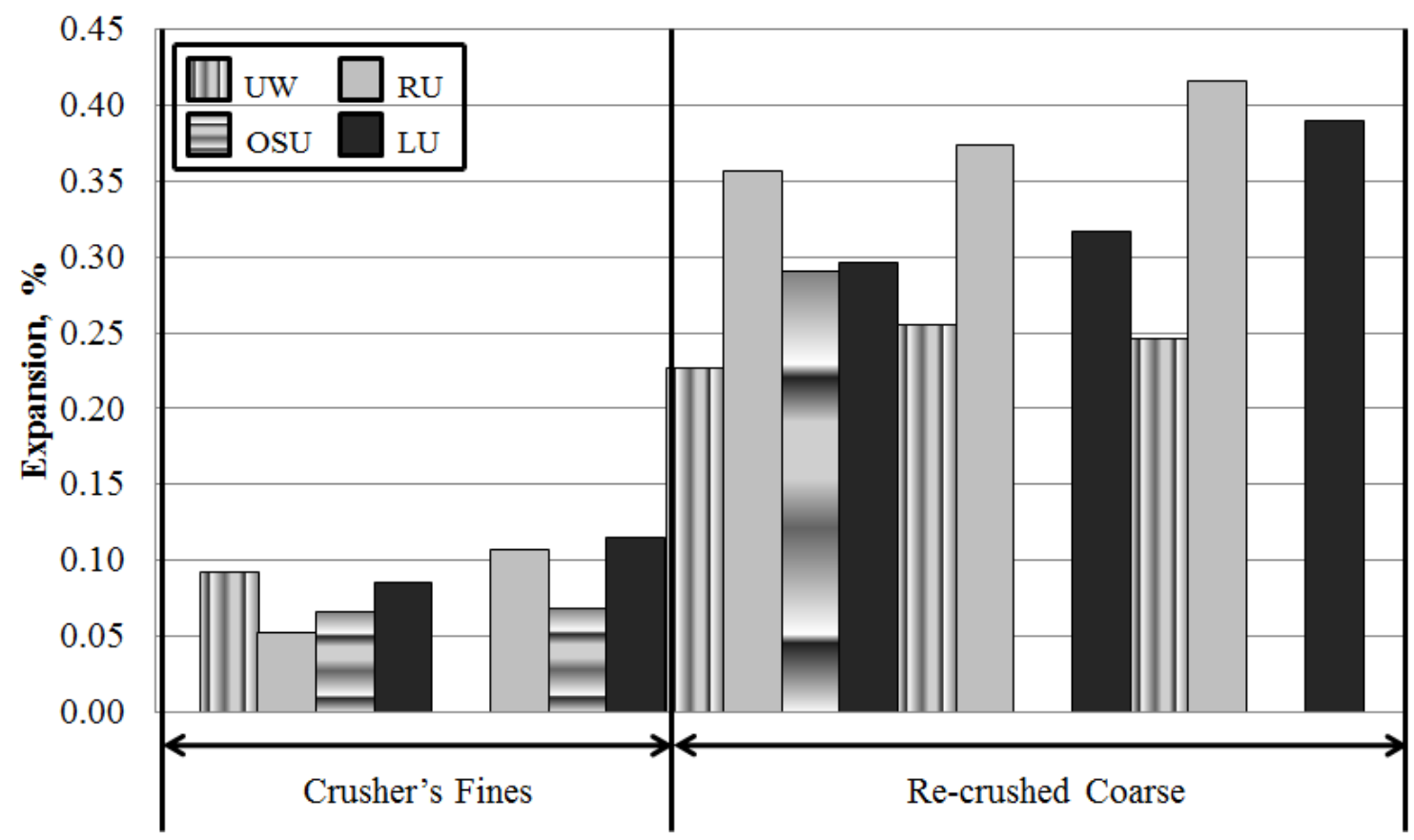

Figure 7-10: Fourteen-day results from each laboratory for $100 \%$ Springhill RCA 


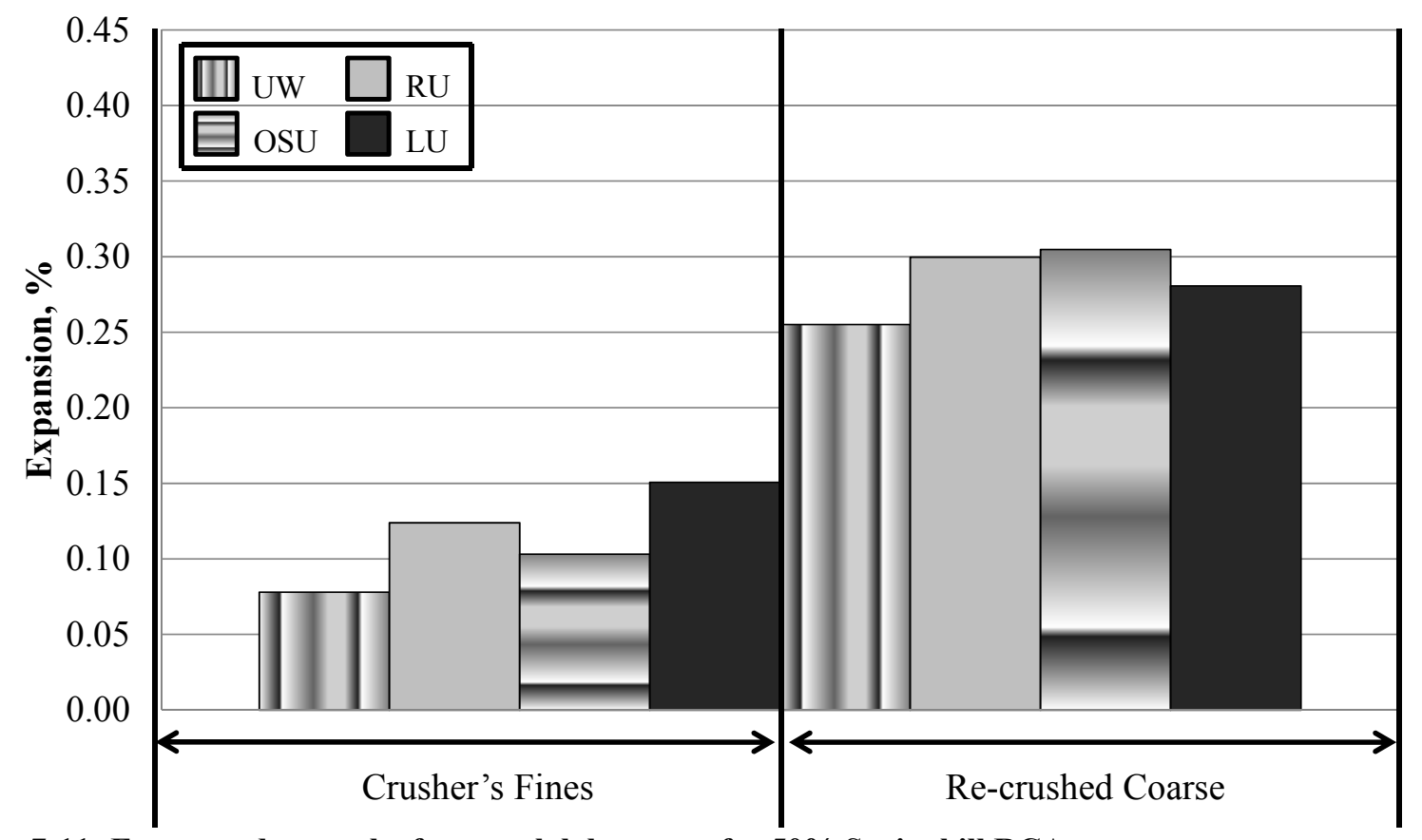

Figure 7-11: Fourteen-day results from each laboratory for $\mathbf{5 0 \%}$ Springhill RCA

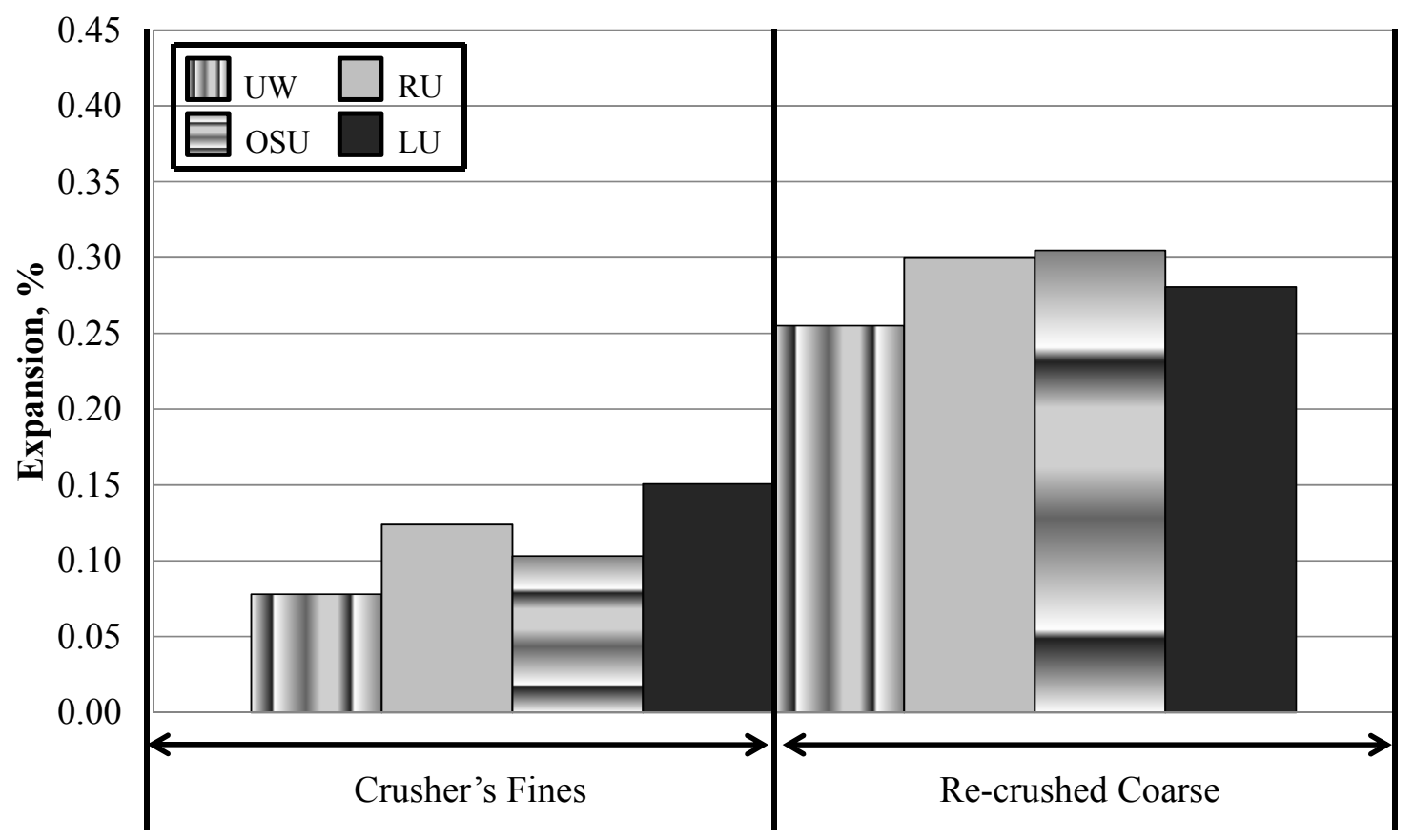

Figure 7-12: Fourteen-day results from each laboratory for 25\% Springhill RCA 


\subsection{DOT RCA USE SURVEY}

\section{O T R E C - Project 339}

\section{Durability Assessment of Recycled Concrete Aggregate}

Dear Department of Transportation Representative, You have been selected based on your expertise related to sustainability and the use of recycled concrete as aggregate (RCA) in your organization. We are hopeful that you will help us by participating in a survey related to how your organization uses and assesses RCA. The feedback that you provide will be used to develop a free information technology systems (such as an online tool, database etc.) that will enable the industry to have easy access to the specific information enabling the cost-effective and safe use of recycled concrete aggregate across transportation related construction projects. If you are willing to participate in this survey please read and sign the informed consent form and fill out the survey below. The survey can be emailed to: concrete@oregonstate.edu. If you wish to send a hard copy you may do so to the provided address below.

There are three sections in this survey. The first section asks questions related to sustainability and the use of RCA within your DOT. The second section is specifically directed toward determining the type of information that a database or online tool would contain to be most useful for improving the usage of RCA in new construction. The final section allows you to provide direct feedback, suggestions and comments. The estimated time to complete this survey is approximately 30 minutes or less.

Thank you for your time.

Sincerely,

OSU Concrete team 


\section{SECTION 1: Sustainability and Use of RCA}

Please rank the following:

\begin{tabular}{ll}
$\mathbf{1}$ & -Strongly Disagree (or no) \\
\hline $\mathbf{2}$ & -Disagree \\
\hline $\mathbf{3}$ & -Neutral \\
\hline $\mathbf{4}$ & -Agree \\
\hline $\mathbf{5}$ & -Strongly Agree (or yes)
\end{tabular}

$\begin{array}{lccccc}\text { Sustainability is important to your DOT. } & \mathbf{1} & \mathbf{2} & \mathbf{3} & \mathbf{4} & \mathbf{5} \\ & \mathbf{C} & \mathbf{C} & \mathbf{C} & \mathbf{C} & \mathbf{C}\end{array}$

Our DOT has specific guidelines for the use of RCA in new construction. Would access to a database with information regarding sources of RCA be of benefit to your DOT?

Would your DOT use a database containing information regarding RCA sources, material properties, and performance history?

The use of RCA in new concrete will negatively affect the economics of transportation related construction projects.

The use of RCA in new concrete will positively affect the economics of transportation related construction projects.

Would such a database be beneficial and increase the use of RCA throughout your organization?

When determining whether or not to use RCA, would your DOT consider both cost and embodied energy to assess the benefits?

Do you believe that government incentives such as tax breaks or LEED credit could effectively promote the use of RCA?

\section{SECTION 2: Specific Information to be collected within the database}

The DOT has an interest in Recycled Concrete Aggregate (RCA) in: 
(Check all that apply)

$\begin{array}{ll}\square & \text { Fill material } \\ \square & \text { Base material } \\ \square & \text { Subbase material } \\ \square & \text { Pavements } \\ \square & \text { Sidewalks } \\ \square \quad \text { Structural concrete } \\ \square \quad \\ \square\end{array}$

The following types of information are under consideration as fields or input values in the new online database tool. Please check all that you think are relevant. You may select as many as possible. You may also provide additional suggestions in Section 3 of this survey.

$\square$ Coarse aggregate type

$\square$ Coarse aggregate volume/mass

$\square$ Fine aggregate type

$\square \quad$ Fine aggregate volume/mass

$\square$ Cement type

$\square \quad$ Cement type volume/mass

$\square \quad$ Water to cement ratio (w/cm)

$\square$ SCM type

$\square \quad$ SCM type volume/mass

$\square$ Structural element RCA derived from

$\square$ Volume of RCA and/or mass of RCA

$\square \quad$ Reason taken out of service

$\square$ Existing deterioration

Air entrainment and dosage rate

$\square$ Condition of RCA (rebar, wire mesh, fibers, etc.)

$\square$ Years in service (for RCA)

Please select the letters associated with the answers that best represent the stance of your DOT:

This database would be most useful if it were to track RCA in the form of: 

C a) New concrete
C b) Existing concrete
C c) Out of service concrete
C d) Rubbalized concrete

Which of the following are the biggest barriers to the use of recycled concrete aggregate?

C a) Economics

C b) Social issues

C c) Initial construction costs

C d) Life cycle analysis (LCA)

C e) Standards

C f) Testing

C g) Specifications

C h) Perception

Please rank in an order of importance that best represents the stance of your DOT:

Which of the following characteristics of an RCA source would enable you to use it most beneficially?

$\square$ Strength

$\square$ Durability

$\square$ Mixture design

$\square$ Presence of epoxy

$\square$ Source

Please rank following environmental issues related to a source of RCA in order of importance to your DOT's decision making strategy:

$\square$ Environmental location (ie. inside or outside)

$\square$ Why it was taken out of service

$\square$ Age

$\square$ Producer

$\square$ Methodology

Were repairs performed and if so in what volume

$\square$ Existing condition

\section{SECTION 3: Suggestions and comments}


Please describe what software or internet format you believe would be the most successful way for users to access the program's information. Please offer the names of specific software that you would like to use such a program with, or a format of internet access that would most suit your needs. (Eg. A website, a Microsoft access program, Microsoft Excel etc. )

What ways of searching would be most useful for you? (Eg. by location, by mix design etc. )

Please use the below area if you would like to expand on your ideas or offer other suggestions for the development of such a tool.

Thank you for completing the survey.

Sincerely,

Jason H. Ideker, Assistant Professor and Kearney Faculty Scholar 



\section{GOTREC \\ AND EDUCATION CONSORTIUM}

P.O. Box 751

Portland, OR 97207

OTREC is dedicated to stimulating and conducting collaborative multi-disciplinary research on multi-modal surface transportation issues, educating a diverse array of current practitioners and future leaders in the transportation field, and encouraging implementation of relevant research results. 